\title{
Comparisons of radiation-circulation coupling over the tropical and subtropical ocean between AMIP6 and CMIP6
}

\author{
Jui-Lin F. Li ${ }^{1, *}$, Kuan-Man Xu ${ }^{2}$, Wei-Liang Lee ${ }^{3}$, Jonathan Jiang ${ }^{1}$, Yi-Hui Wang ${ }^{4}$, Eric Fetzer ${ }^{1}$, \\ Jia-Yuh $\mathrm{Yu}^{5}$, and Li-Chiao Wang ${ }^{5}$ \\ ${ }^{1}$ Jet Propulsion Laboratory, California Institute of Technology, Pasadena, California, USA \\ ${ }^{2}$ Science Directorate, NASA Langley Research Center, Hampton, USA \\ ${ }^{3}$ RCEC, Academia Sinica, Taipei City, Taiwan \\ ${ }^{4}$ California Polytechnic State University, San Luis Obispo, USA \\ ${ }^{5}$ Department of Atmospheric Sciences, National Central University, Taoyuan City, Taiwan
}

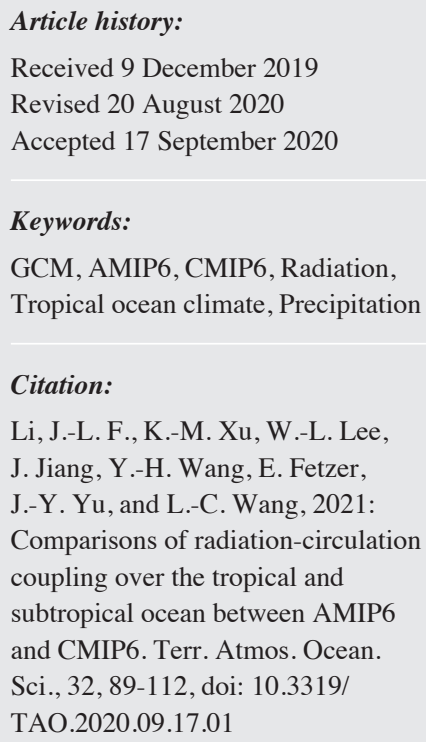

\section{Citation:}

Li, J.-L. F., K.-M. Xu, W.-L. Lee, J. Jiang, Y.-H. Wang, E. Fetzer, J.-Y. Yu, and L.-C. Wang, 2021: Comparisons of radiation-circulation coupling over the tropical and subtropical ocean between AMIP6 and CMIP6. Terr. Atmos. Ocean. Sci., 32, 89-112, doi: 10.3319/ TAO.2020.09.17.01

\begin{abstract}
This study compares radiation-circulation coupling over tropical and subtropical oceans by examining ice water path, radiation, low-level wind, and precipitation fields from the uncoupled prescribed sea surface temperature AMIP6 and the fullycoupled CMIP6 historical runs. Ice water path of the CMIP6 ensemble shows a closer agreement than the AMP6 ensemble, particularly in the subtropics. The inclusion of falling ice (snow) radiative effects (FIREs), in general, improves simulation of radiation, low-level wind, and precipitation fields over the northwest Pacific, Southeast Pacific Convergence Zone (SPCZ), equatorial eastern Pacific and Atlantic Intertropical Convergence Zone (ITCZ). When both AMIP6 and CMIP6 models are divided into two groups with inclusion and exclusion of FIREs, the impact of FIREs is most pronounced in ITCZ and the subtropical trade-wind regions in CMIP6 but over the tropical Pacific and SPCZ in AMIP6. This suggests that active ocean plays a significant role in radiation-circulation coupling. The CMIP6 models with FIREs have less over-estimated biases in upward longwave radiation over the convective zones in Pacific and Atlantic and less low-level divergence of anomalous flows over convective zones, i.e., stronger trade winds. The circulation changes stronger in CMIP6 over the trade wind regions than in AMIP6, which suggests that the role of active ocean is important in testing an improved physical process in models. This conclusion is also supported by more systematic improvements in groups of models with inclusion of FIREs in CMIP6 than in AMIP6, hinting the important roles of FIREs in radiationcirculation coupling.
\end{abstract}

\section{INTRODUCTION}

Clouds, convection, precipitation and their effects on radiation play important roles in global weather and climate. It is a great challenge to investigate them properly using available observations and modeling approaches [e.g., Stephens 2005; IPCC 2007; International Panel on Climate Change (IPCC) Fifth Assessment Report (AR5), Working Group 1, http://www.ipcc.ch/report/ar5/wg1). One of the uncertainties is the representation of cloud and precipitation masses, and their interactions with radiation in the general

\footnotetext{
* Corresponding author

E-mail:jli@jpl.nasa.gov
}

circulation models (GCMs), such as those in the previous Phase 5 of the Coupled Model Intercomparison Project (CMIP5: Taylor et al. 2012) as well as in the current phase 6 (CMIP6: Eyring et al. 2016). Traditionally, these GCMs represent cloud and precipitation with a number of discrete hydrometeor categories (e.g., cloud liquid, cloud ice, falling ice, and rain) in both stratiform and convective cloud parameterizations prognostically or diagnostically and only the cloud liquid and cloud ice masses in the stratiform regions are considered in radiative flux calculations in the models, i.e., the radiative impacts of falling ice (snow) and liquid (rain) and all hydrometeors in the convective regions are neglected (Waliser et al. 2009, 2011; Li et al. 2012). 
The role played by FIREs has been explored both from an observationally-based offline radiative transfer calculation using CloudSat-CALIPSO data (Waliser et al. 2011) and by many studies using a fully-coupled climate model (Li et al. 2012, 2013, 2014a; Michibata et al. 2019) and forecast system using ECMWF Integrated Forecasting System (IFS) (Li et al. 2014b). Up to date, a growing number of the GCMs participating in the ongoing CMIP6 that have considered the falling ice (specifically, large ice particles) radiative effects (FIREs). Li et al. (2020) assessed overall progress in the context of CMIP5 to CMIP6, focusing on the differences in CMIP6 models with and without FIREs in CMIP6 models over tropical and subtropical Pacific and Atlantic Oceans. They found that CMIP6 models with FIREs have reduced biases in radiation, circulation, precipitation, and sea surface temperature (SST), compared to those without FIREs, especially, over the trade wind regions. In summary, these studies showed that inclusion of FIREs influencing the radiation-circulation patterns over tropical Pacific Ocean. These results indicate that the large ice particles, with its radiative effects, make an indispensable contribution to improving the reliability of climate modeling.

As a brief summary of the impacts of FIREs, highlighted in the Supplementary Information (SI), Li et al. (2013, 2014a, b, 2015, 2016), noted that persistently systematic biases in CMIP3 (Phase 3 of CMIP) and CMIP5 models against observations occur in conjunction with an underestimation of the total ice water path (TIWP) defined as the sum of convective core ice path (CIP), precipitating ice water path (PIWC), and cloud ice water path (CIWP) [shown in Fig. 13 of Li et al. (2013)]. In particular, sensitivity tests using the Department of Energy (DOE) and National Center for Atmospheric Research (NCAR) coupled Community Earth System Model (CESM1) with Community Atmosphere Model Version 5 (CAM5) showed that ignoring the FIREs could contribute to systematic biases over the Pacific Ocean. TIWP underestimated by the CMIP5 models could be up to $85 \%$ against CloudSat-CALIPSO estimate (Fig. S1b), producing excessive downward shortwave (SW) radiation at the surface (RSDS: Fig. S1c), weaker reflected SW (Fig. S1a), and excessive TOA outgoing longwave (LW) radiation (Fig. S1d) in the heavily precipitating regions such as ITCZ/SPCZ. The FIREs also impact the vertical profile of radiative heating rate and the overturning circulation. The LW radiatively unstable gradient (Fig. S3) produces the excessive upper-level ascending motions aloft and slightly descending motions below. The increased updraft strength is compensated by that of enhanced downdraft, leading to grid-box anomalous outflows shown in Fig. S4. The compensating moist condensational heating/ cooling at $300 / 850 \mathrm{hPa}$ (black profile) is associated with the ascending motions above $650 \mathrm{hPa}$ whereas the condensational cooling (rain re-evaporative cooling associated with convective downdraft) is associated with the descending motions below $650 \mathrm{hPa}$. This low-level descending motion produces anomalous low-level divergence (Figs. S4 and S5) and, as a result, leading to anomalous advection of low-level moist and warm air originated from the warm pool and the ITCZ/SPCZ to the north/south central Pacific regions. The FIREs are particularly apparent over these strongly precipitating and/or convectively active regions (e.g., mid-latitudes storm tracks, warm pool, and ITCZ/SPCZ). For more details, see Supplementary Information (SI).

Despite the efforts of extensive previous works, most coupled GCMs still have difficulties in simulating realistic SST (e.g., Meehl et al. 2005; Lin 2007; Randall et al. 2007; De Szoeke and Xie 2008), surface heat fluxes (e.g., Li and Xie 2014), and surface wind stress (e.g., Li et al. 2015). The aforementioned biases are expected to be associated with biases in clouds, radiation and precipitation in the atmosphere. Previous studies (e.g., Li and Xie 2012) indicate that these biases can be caused by the surface wind stress bias and/or that of surface heat flux lost via evaporation from a coupled atmosphere-ocean feedback. They showed that tropical mean SST biases in coupled GCMs originate from cloud biases in atmospheric models by comparing the pairs of models from CMIP and uncoupled Atmospheric Model Intercomparison Project (AMIP). They found that the double ITCZ precipitation errors and excessive easterly wind biases are absent in AMIP simulations and resulted from the interaction with the thermocline. Traditionally, AMIP models have been used in testing and tuning parameterization schemes of physical processes, including stratiform cloud microphysics, before the schemes are implemented in their fully-coupled counterparts.

In the past few years, the importance of FIREs has been gradually noticed by modeling groups worldwide (e.g., Gettelman et al. 2010; Michibata et al. 2019), which results in more GCMs participating in CMIP6 than in CMIP5 that have considered either diagnostically or prognostically the effects of falling ice (snow) and falling liquid (rain) in the radiation calculations. This progress provides an opportunity to compare the changes in the simulation fields between two groups of models with FIREs (SON) or without FIREs (NOS) that have performed both uncoupled AMIP6 (phase 6 of AMIP) and fully-coupled CMIP6 simulations. By comparing these groups of models, we will be able to identify the influence of the FIREs in AMIP6 and CMIP6 simulations. The difference in the influence between AMIP6 and CMIP6 can reveal the role of interactive ocean, which provides additional feedbacks to the radiation-circulation changes due to FIREs. The results of this comparison can reconfirm the importance of FIREs found earlier with a weather forecast model ( $\mathrm{Li}$ et al. 2014a) and sensitivity tests with a single coupled GCM (Li et al. 2014b). It should be, however, pointed out that the differences between AMIP6 and CMIP6 FIREs off (NOS) and on (SON) model groups also include the indirect changes related to the FIREs, for 
example, the local circulation changes, horizontal resolution and other changes related to model improvements. The focus of this study is to examine the radiation-circulation coupling that is resulted from the inclusion of FIREs in AMIP6 and CMIP6 over oceans and to see the differences with and without interactive ocean, including Pacific and Atlantic oceans between the latitude belts of $60^{\circ} \mathrm{S}-60^{\circ} \mathrm{N}$.

In section 2, we describe the general information of AMIP6 and CMIP6 models. Observational data used in this study are described in section 3 . In section 4 , we illustrate and discuss the patterns of radiation fields, low-level winds, and precipitation against observations. Section 5 provides a summary and conclusions.

\section{AMIP6 AND CMIP6 MODELS}

The specific experimental scenario used is the CMIP6 historical $20^{\text {th }}$ century simulation (1850 to 2014), which uses the observed $20^{\text {th }}$ century greenhouse gas, ozone, aerosol, and solar forcing (Eyring et al. 2016). We used 20 model outputs available with the same atmospheric models from CMIP6 and uncoupled AMIP6 (see Table 1) for this study, with the ensemble mean being denoted as AM6/CM6. Among them, 14 models exclude FIREs (left column in Table 1) with their ensemble means being denoted as AM6NOS/CM6NOS; while 6 models include FIREs denoted as AM6SON/CM6SON (right column in Table 1).

AM6SON/CM6SON models use the atmospheric component (CAM6) in CESM2 series contains a two-moment prognostic cloud microphysics (MG2) scheme (Gettelman and Morrison 2015). The major innovation in MG2 is to carry prognostic precipitation species - falling liquid (rain) and falling ice (snow) - in addition to cloud condensates (cloud ice and cloud liquid). The SON subgroup used includes CESM2, CESM2-FV2, CESM2-WACCM, CESM2WACCM-FV2, and NorESM2-MM with MG2 and TaiESM with CESM1-CAM5 cloud microphysics (Gettelman et al. 2010) with diagnostic snow. SON models use separate ice and falling ice contents with different effective ice diameters to calculate ice-cloud radiative properties.

The simulation time period for analyses is 1980 - 2014 in order to match closely with available reanalysis of lowlevel winds from ECMWF ERA5, precipitation data from Global Precipitation Climatology Project (GPCP) and the radiation flux data from the Clouds and the Earth's Radiant Energy System (CERES). For the purposes of comparison, both the GCM and observational data sets are re-gridded onto a common horizontal resolution of $2^{\circ}$ latitude by $2^{\circ}$ longitude. Finally, if a model provided an ensemble of simulations, only one of them was chosen for the purposes of this evaluation.

\section{REFERENCE DATASETS}

\subsection{Surface Wind}

While there is no surface wind output available for AM6SON models, $1000 \mathrm{hPa}$ winds are used to compare against low-level wind (at $1000 \mathrm{hPa}$ ) taken from the new

Table 1. List of AMIP6 and CMIP6 models used in this study separated according to whether they exclude falling ice radiative effects (i.e., no falling snow radiative effects, NOS) or whether they include these effects (i.e., prognostic falling ice mass and their radiative effects on, SON). This subset is all those for whom the r1i1p1 simulations are available for all the used scenarios and whose output included all necessary surface flux and sea ice fields. *TaiESM2 has a diagnostic falling ice radiative effect.

\begin{tabular}{cc}
\hline AMIP6/CMIP6 models without FIRE (NOS) & AMIP6/CMIP6 Models with FIRE (SON) \\
\hline ACCESAS-ESM & NorESM2-MM \\
BCC-CSM2-MR & CESM2-FV2 \\
BCC-ESM1 & CESM2-WACCM-FV2 \\
CAM-CSM1-0 & CESM2 \\
CanESM5 & CESM2-WACCM \\
CNRM-CM6-1 & \\
CNRM-ESM2-1 & \\
IPSL-CM6A-LR & \\
MIROC6 & \\
MRI-ESM2-0 & \\
INM-CM4-8 & \\
INM-CM5-0 & \\
NESM3 & \\
MPI-ESM-1-2-HAM & \\
\hline
\end{tabular}


ECMWF ERA5 reanalysis (Hersbach and Dee 2016). The ERA5 IFS and its assimilation system underwent major modifications including higher spatial and temporal resolutions (Hersbach and Dee 2016), an improved radiation scheme (Urraca et al. 2018), cloud schemes, cloud overlap assumptions, and prognostic falling ice and rain which now interact with radiation (Forbes et al. 2011; Copernicus Climate Change Service 2017). The time period of 1980 - 2014 is used for this study.

\subsection{Cloud Ice}

The vertically-resolved cloud hydrometeor profiles of 2C-ICE data product (Deng et al. 2010, 2013) derived from CloudSat (Stephens et al. 2008; Austin et al. 2009) provides a reference for the global evaluation of simulated CIWP (e.g., Waliser et al. 2009; Gettelman et al. 2010; Li et al. 2012). CloudSat-CALIPSO has both daytime and nighttime observations available only for the 2007 - 2010 period. Further details of this data product will be provided in section 4.1.

\subsection{Radiation}

The TOA radiative fluxes are from CERES Energy Balanced and Filled (CERES-EBAF, Loeb et al. 2009, 2012) data product and the surface flux radiative fluxes are constrained by TOA CERES-EBAF adjustments (Kato et al. 2011, 2012, 2013). Fourteen year means for the period of 2001 - 2014 are used for evaluations of the AMIP6 and CMIP6 model outputs.

\subsection{Precipitation}

The GPCP Version 2.3 monthly precipitation dataset, from January 1980 through May 2014, is used (Adler et al. 2003 , 2018). GPCP precipitation data are available from the NOAA/OAR/ESRL PSD, Boulder, CO, USA (https://www. esrl.noaa.gov/psd/). The monthly data provide a consistent global precipitation description by integrating various satellite data sets over land and ocean with a gauge analysis over land to produce estimated monthly rainfall on a 2.5 -degree global grid. The careful combination of satellite-based rainfall estimates provides the most complete analysis of rainfall available to date over the global oceans, and adds necessary spatial details to the rainfall analyses over land. In addition to the combination of these data sets, estimates of the uncertainties in the rainfall analysis are provided as a part of the GPCP product.

\section{RESULTS}

\subsection{Annual Mean Bias}

\subsubsection{Evaluation of Ice Water Path}

The ice water path data is from $\mathrm{Li}$ et al. (2012) and has been widely used (e.g., Gettelman et al. 2010). The data was derived from the 2C-ICE product from CloudSat-CALIPSO estimates (Deng et al. 2010, 2013). A flag-based partitioning method (Waliser et al. 2009; Li et al. 2012) was used to sort ice mass retrievals into two categories: (i) larger particle mass, which is considered to be precipitating stratiform and convective snow; and (ii) smaller particle mass, which is considered to be quasi-suspended in clouds.

As discussed previously, the dominant contribution to the total ice water path (TIWP) is from the falling ice in both the CloudSat data ( $\mathrm{Li}$ et al. 2012) and models with FIREs (Li et al. 2015, 2016). The TIWP is about two-thirds contributed by falling ice (as known as snow) water path (SWP) but only one-third by CIWP. The missing SWP results in large biases of TIWP in the NOS group of AM6 (Fig. 1a) and CM6 (Fig. 1b), which have very similar spatial patterns. Note that there is no falling ice path included TIWP output in the SON group of models from CMIP6 archive. As noted in earlier studies, a GCM only including CIWP in its radiation calculation misses a significant part of TIWP shown in Figs. 1a and b, which can impact the radiative energy transports in the atmosphere, as shown in Waliser et al. (2009), Gettelman et al. (2010), Li et al. (2012), and Michibata et al. (2019). Shown in Fig. 1c is the cloud only ice water than (IWP) or CIWP biases for AM6 and CM6, which are underestimated compared to the CloudSat 2C-ICE estimates over convective zones. Both AM6 and CM6 agree well in the tropics and extra-tropics, but are biased low over the ITCZ, SPCZ, and Tropical Warm Pool (Figs. 1d and e) while the absolute biases of TIWP and CIWP in AMIP6 are larger than in CMIP6 (Figs. 1c and f), indicating slight improvements of cloud ice simulation from AMIP6 to CMIP6.

\subsubsection{Impacts of the Falling Ice Radiative Effects on Radiation}

Li et al. (2020) examined the potential links between IWP, radiation, circulation, SST and precipitation over the Pacific and Atlantic Oceans resulting from the FIREs from CMIP6 historical simulations. They found that as a group, CMIP6 models with FIREs have reduced biases in radiation, circulation, precipitation and SST, with improvements over the group of models without FIREs and multi-model means (MMMs) of CMIP6. In this section, we will further examine the changes in the radiation budget components from uncoupled AM6 to fully coupled CM6 to explore the role of interactive ocean and the differences in the changes from NOS to SON between AMIP6 and CMIP6. We will present (1) biases of AM6 and CM6 against observations, (2) biases for their NOS and SON groups of models, (3) changes in the absolute biases from NOS to SON, and (4) changes in the absolute biases from AM6 to CM6. The comparison between AMIP6 and CMIP6 groups will allow us to see the role of interactive ocean in changing radiative fluxes resulting 

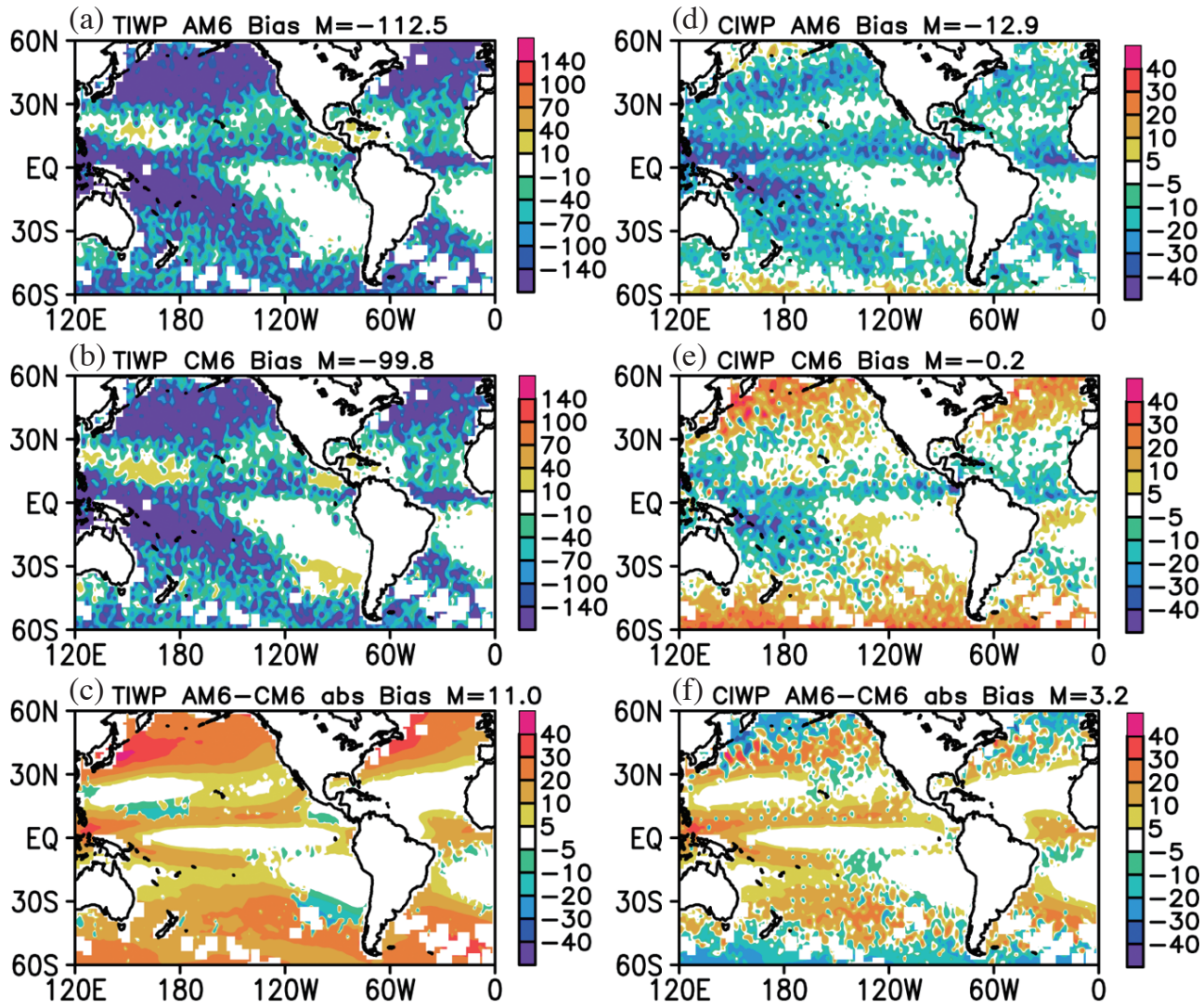

Fig. 1. (a) Bias of cloud only ice water path (CIWP: $\mathrm{g} \mathrm{m}^{-2}$ ) from models which have prognostic cloud ice only IWP (CIWP) in (a) AMIP6 (AM6), (b) same as (a) but for CMIP6 (CM6) against total ice water path (falling ice + floating cloud ice) derived from 2C-ICE CloudSat-CALIPSO estimates for annual mean (2007 - 2010), (c) absolute TIWP bias between AMIP6 and CMIP6 [abs(AM6-obs) - abs(CM6-obs)] . (d) - (f) same as (a) - (c) but against cloud ice only derived from 2C-ICE CloudSat-CALIPSO estimates for annual mean (2007 - 2010).

directly from FIREs over the convective zones and indirectly over the trade wind regions, as reported in Li et al. (2020).

Same as in Waliser et al. (2009) and Li et al. (2013), over the convective zones, there are positive biases of 4 $8 \mathrm{~W} \mathrm{~m}^{-2}$ in upward longwave radiation (RLUT) in AM6 (Fig. 2a) and AM6NOS (Fig. 2b) and has broader areas of positive bias in AM6SON (Fig. 2c). Over the trade-wind regions, the magnitudes of low-biased RLUT are reduced to under $-4 \mathrm{~W} \mathrm{~m}^{-2}$ in AM6SON from AM6NOS. The improved RLUT from AM6NOS to AM6SON are found over trade wind regions (Fig. 2d) up to $16 \mathrm{~W} \mathrm{~m}^{-2}$. With the coupled ocean, RLUT biases from CM6NOS (Fig. 2f) to CM6SON (Fig. 2g) are reduced with the absolute values $8-20 \mathrm{~W} \mathrm{~m}^{-2}$ (Fig. 2h) over most of the domain, slightly larger than the AMIP6 counterparts. Except over tropical western Pacific (TWP) and southern Pacific and Atlantic trade wind regions, the RLUT biases in AM6 and its NOS and SON groups are higher than CM6, CM6NOS and CM6SON, respectively (Figs. 2i, j, k). The spatial patterns in these absolute biases are sharply different from those due to FIREs in either AMIP6 or CMIP6 (Figs. 2d and h), with more significant improvements in the convective zones and the subtropics of CMIP6 relative to AMIP6 from NOS to SON groups.
The impact of FIREs on TOA reflected shortwave radiation (RSUT) can be seen over the entire analysis domain (Fig. 3) except in the regions south of $30^{\circ} \mathrm{S}$. There is a remarkable reducing high-biased RSUT over trade wind regions from AM6NOS (Fig. 3b) to AM6SON (Fig. 3c) and from CM6NOS (Fig. 3f) to CM6SON (Fig. 3g), with reduced magnitudes in biases from $8-16 \mathrm{~W} \mathrm{~m}^{-2}$ for AM6NOS (Fig. 3b) to $-8-8 \mathrm{~W} \mathrm{~m}^{-2}$ for AM6SON (Fig. 2c) and from $8-20 \mathrm{~W} \mathrm{~m}^{-2}$ for CM6NOS (Fig. 3f) to $-8-16 \mathrm{~W} \mathrm{~m}^{-2}$ for CM6SON (Fig. 3g). The positive absolute biases of RSUT indicate improvement in AM6SON (Fig. 3d) and CM6SON (Fig. 3h) with the inclusion of FIREs, in particular, over the subtropics. The improvement is shown in larger magnitudes over larger areas with the coupled ocean. Lastly, Figs. 3i - k show the differences of the absolute bias between AM6 and CM6 and their NOS and SON groups. The absolute biases in RSUT are generally smaller in AMIP6 than in CMIP6, similar to those of RLUT, hinting that interactive ocean does not systematically improve the simulation of RSUT except over northwest and southeast Pacific and SPCZ. The prescribed SSTs in AMIP run is helpful with the simulation of stratocumulus clouds off the coasts.

The differences in downward SW at the surface 
(a) RLUT AM6 Bias
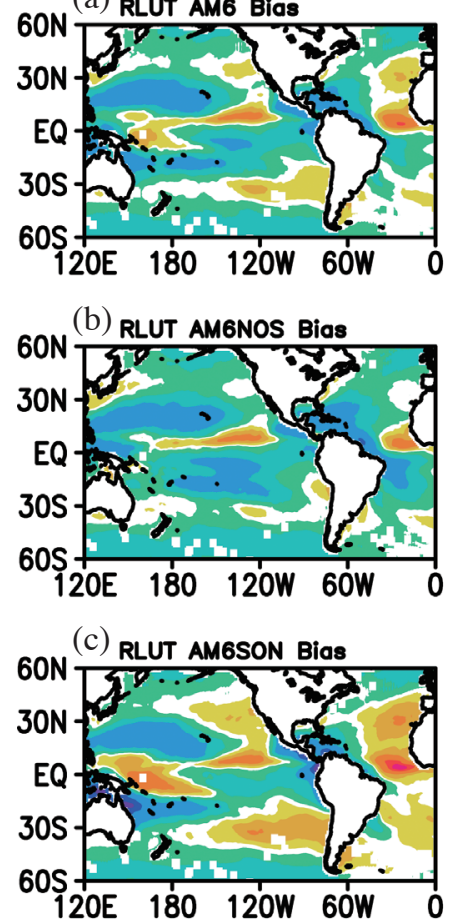

(e) RLUT CM6 Bias
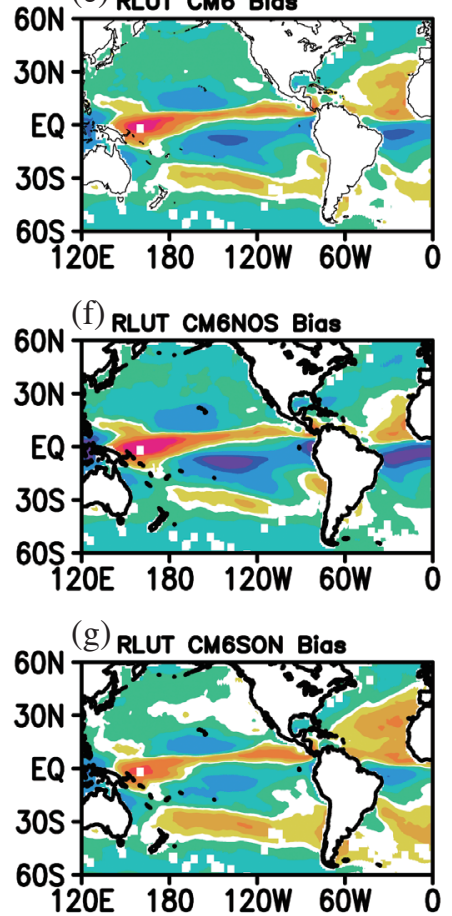
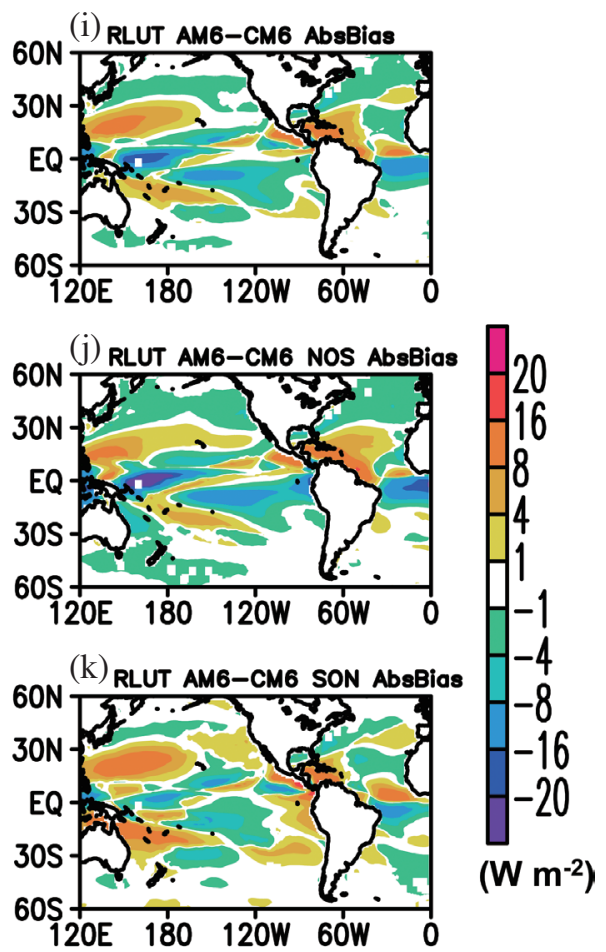

(d) RLUT AM6(NOS-SON) absBiag̊ (h) RLUT CM6(NOS-SON) absBias
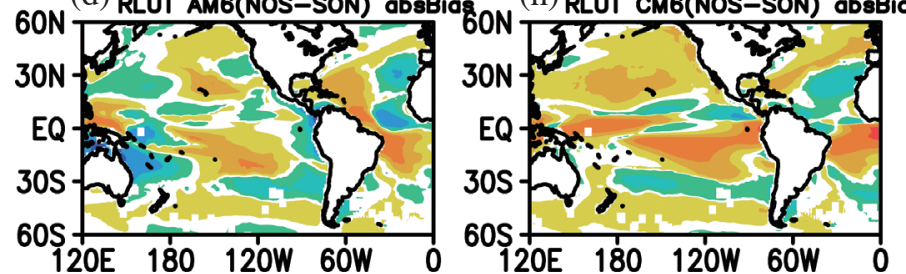

Fig. 2. (a) Time-averaged annual mean bias of AMIP6 (AM6) ensemble mean in radiative fluxes (W $\mathrm{m}^{-2}$ ) for outgoing longwave flux (RLUT) at the top of atmosphere (TOA) against CERES, (b) same as (a) but for bias of AMIP6 without falling ice radiative effects (FIREs) (AM6NOS), (c) same as (b) but for bias of AMIP6 with FIREs (AM6SON), (d) the absolute bias between AM6NOS and AM6SON [AMIP6(NOS-SON)]. (e) - (h) same as (a) - (d) but for CMIP6. (i) the difference of absolute bias between AMIP6 and CMIP6 [abs(AM6-Obs) - abs(CM6-Obs)]. (j) same as (i) but between AM6NOS and CM6SON. (k) same as (i) but for AM6SON and CM6SON. The annual time averaged over 2001 - 2014. 

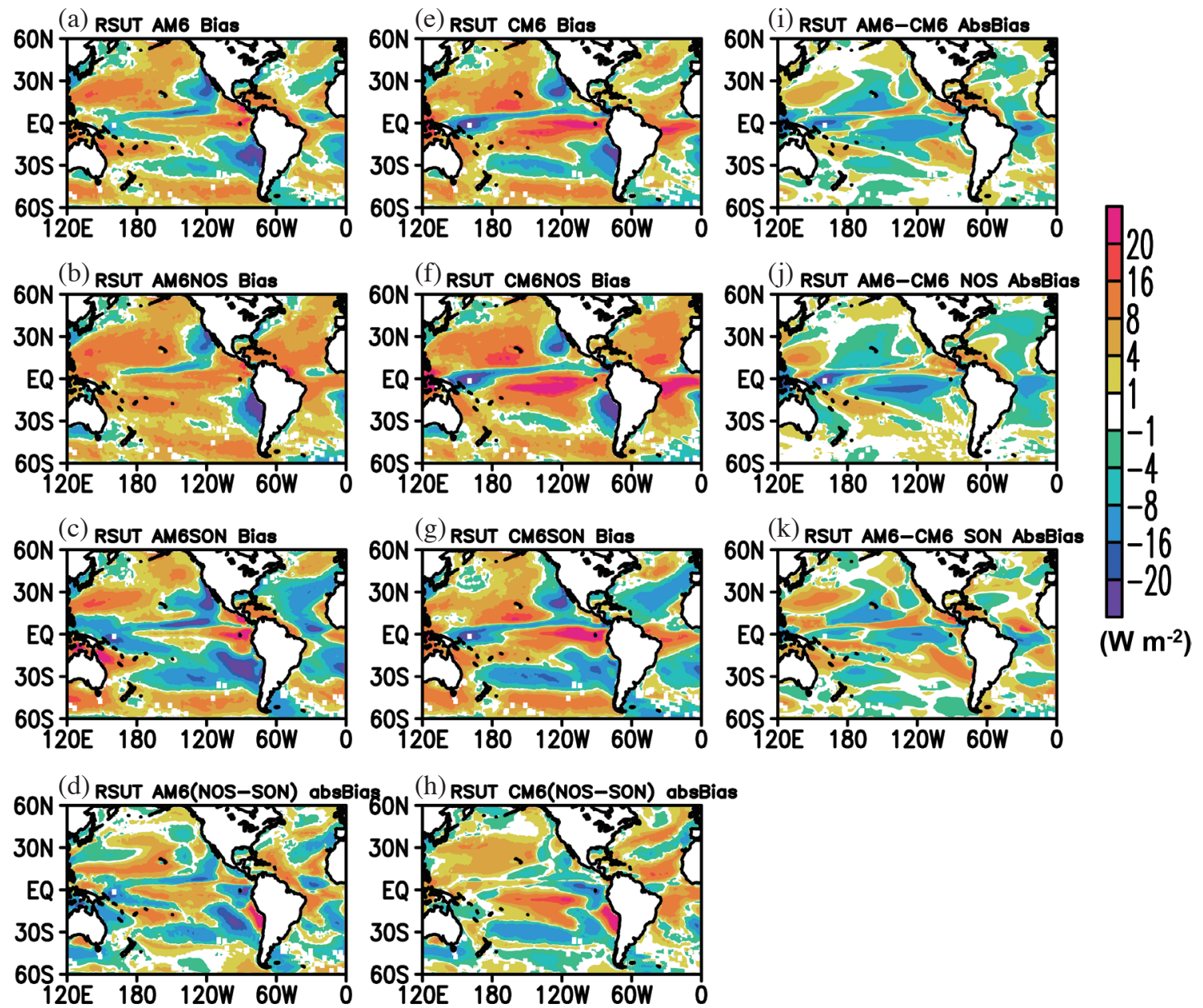

Fig. 3. Same as Fig. 2 but for reflected shortwave flux (RSUT) at the top of atmosphere (TOA) against CERES.

(RSDS) between AM6 and CM6, AM6NOS and AM6SON as well as CM6NOS and CM6SON are shown in Fig. 4. The largest biases appear in low-cloud regions in both Pacific and Atlantic due to instability of models to produce these clouds. The low-biased RSDSs over the trade wind regions are more pronounced in CM6, CM6NOS, and CM6SON (Figs. $4 \mathrm{e}-\mathrm{g}$ ) than their AMIP counterparts (Figs. 4a - c). Over ITCZ and trade wind regions of South Pacific and Atlantic, there are slightly more improvements in RSDS biases with FIREs from CM6NOS to CM6SON (Fig. 4g) than from AM6NOS to AM6SON (Fig. 4h). As in RLUT and RSUT, the improvements from AM6 to CM6 and their groups occur primarily in northwest and southeast Pacific and SPCZ.

The above-mentioned results of RLUT and RSUT in AM6 are consistent with Li et al. (2014b). They found that the forecast differences produced by the uncoupled ECMWF IFS with FIREs on and off essentially exhibit nontrivial impact of TIWP on the radiation fluxes. Lacking falling ice in radiation calculation increases the net radiative flux at the surface (Figs. $4 \mathrm{~d}$ and $\mathrm{h}$ ) and the radiative cooling to outer space (Figs. 2d and h) over the strongly precipitating and convectively active regions, such as the ITCZ/SPCZ regions. This results in excessive net RSUT but less RSDS over the trade wind belts of the tropical Ocean, which are likely due to the circulation changes that impact the lowlevel clouds. This radiation-circulation coupling mechanism is similar to that found from the sensitivity experiments by turning on and off the FIREs in Li et al. (2014a) using the fully coupled NCAR-DOE CESM1-CAM5. The coupling seems to be weaker in AMIP6 than in CMIP6 when SSTs are prescribed, which may reduce the circulation changes resulting from the inclusion of FIREs in AM6SON models.

\subsubsection{Comparisons of Low-Level Circulations Changes}

In Li et al. (2014a), which is summarized in SI, they explored the impacts of FIREs on circulation and precipitation over the tropical Pacific using fully-coupled NCARDOE CESM1-CAM5. For the CESM1 and those CMIP GCMs without FIREs, an overestimation of outgoing LW and downward SW occurs in the convective and heavy 

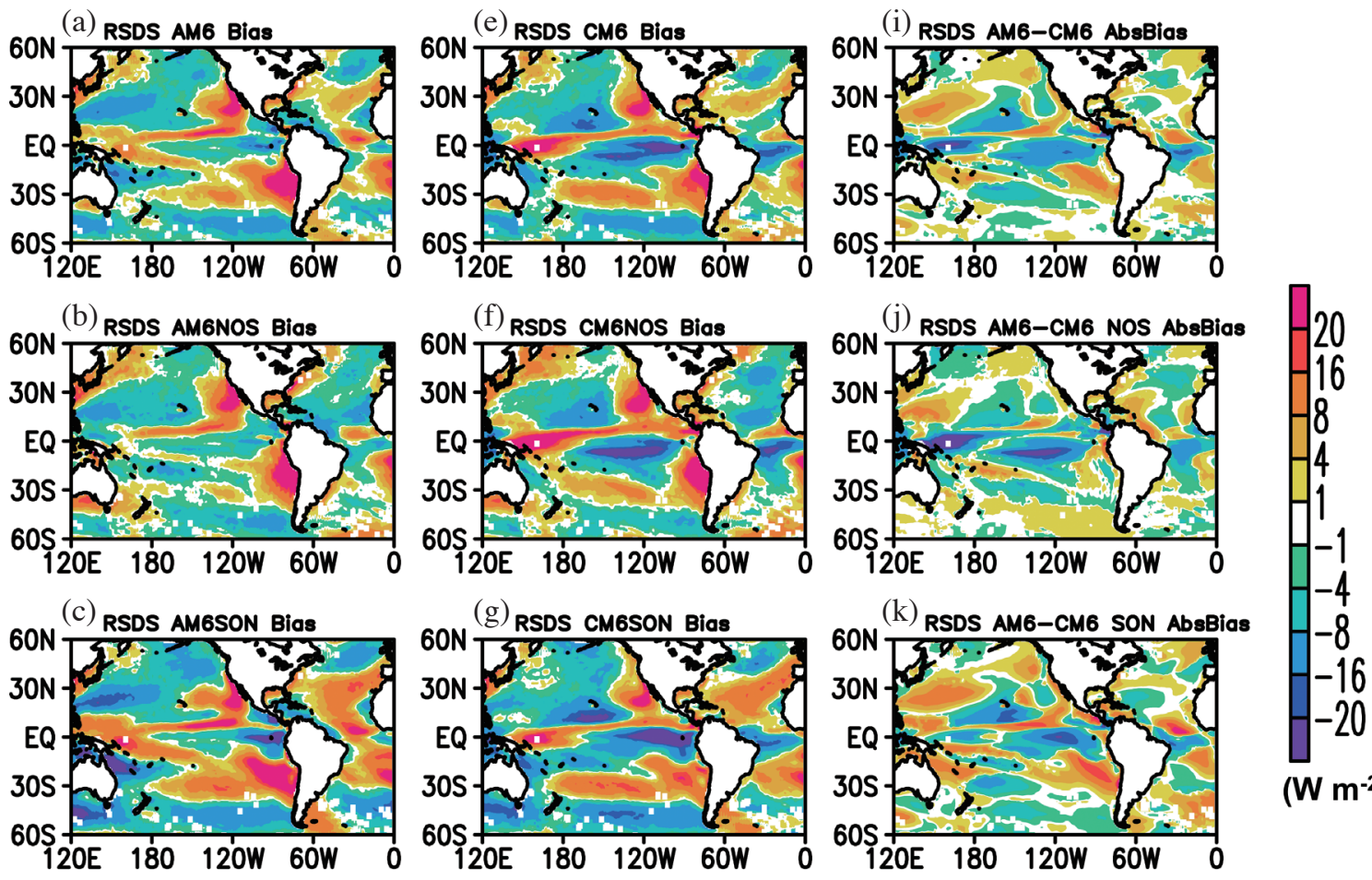

$\left(W^{-2}\right)$

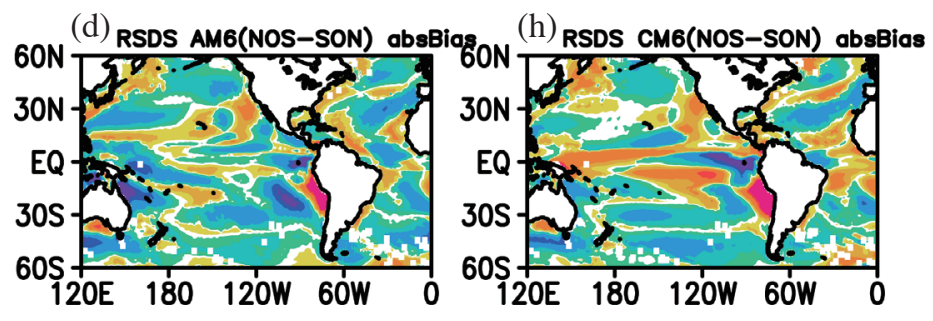

Fig. 4. Same as Fig. 3 but for downward shortwave flux (RSDS) at the surface against CERES.

precipitation regions (e.g., ITCZ, SPCZ, and tropical warm pool), resulting in upper-level LW and net radiative cooling as illustrated in SI Fig. S2. This radiative destabilization produces excessive upper-level ascending motions aloft and slightly descending motions below middle-low levels; increased updraft compensated by enhanced downdraft producing low-level divergence anomaly and, as a result, leading to anomalous advection of low-level moist and warm air originated from the warm pool and the ITCZ/SPCZ to the north/south central Pacific regions. This further implies weaker easterlies and meridional divergence flows along ITCZ and SPCZ over the trade wind regions as shown in the right panel of Fig. S2.

Li et al. (2020) explored the impacts of FIREs on circulation over the tropical Pacific by comparing surface wind stress against QuikSCAT in the CMIP6 models with and without FIREs. They found that models without FIREs simulated westerly and meridional divergent anomalous flow biases from the convective zones toward trade wind areas in the Pacific and Atlantic. These biases are reduced significantly in models with FIREs included with stronger easterly wind stress. The abovementioned bias reduction with FIREs for surface wind stress plays some roles in reducing SSTs biases because weaker trade winds do not stir and cool the ocean much on the flanks of the ITCZ (Li et al. 2015, 2016).

However, there is no surface wind output available for AM6SON models. Instead, we use low-level wind at $1000 \mathrm{hPa}$ against ERA5. Note that the ERA5 wind fields might not use enough observations for data assimilation over oceans so that the reanalyzed wind fields might come partially from the IFS forecasting rather than the assimilated observation.

There is a clear low-level meridional divergence bias along the convective zone in CM6 (Fig. 5c) but not in AM6 (Fig. 5b) against ERA5 winds at $1000 \mathrm{hPa}$. The differences in winds fields at $1000 \mathrm{hPa}$ between AM6NOS and ERA5 (Fig. A1c) shows that there are small biases in AM6NOS, but there are stronger trade winds occurring mainly over the trade-winds regions of AM6SON (Fig. A1d). While there are anomalous meridional divergent flows south of ITCZ in Pacific and Atlantic in CM6NOS (Fig. A1e), but they are reduced in CM6SON (Fig. A1f). This implies that low-level 

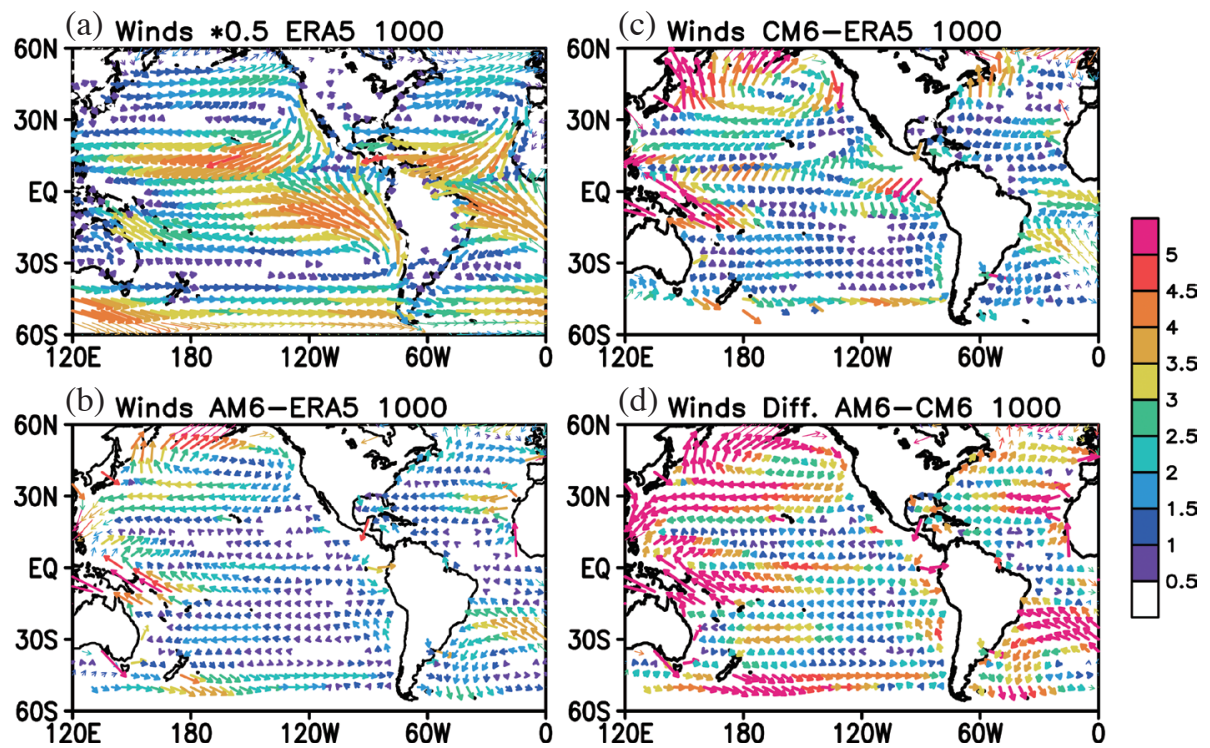

Fig. 5. (a) Annual mean ERA5 winds at $1000 \mathrm{hPa}$, (b)Time-averaged bias of AMIP6 (AM6) for the winds versus ERA5 at $1000 \mathrm{hPa}$, (c) same as (b) but for CMIP6 (CM6). (d) same as (c) but the difference of AMIP6 and CMIP6 (AM6-CM6). The annual time averaged is over 1980 - 2014.

wind bias shown in CM6NOS and CM6 lead to a weakening of local low-level trade winds over most of the tropical Pacific and Atlantic Oceans. Figure 5d shows the difference between AMIP6 and CMIP6 (AM6-CM6), illustrating stronger easterly in AMIP6 with smaller wind biases than CMIP6. This implies that the impacts of interactive ocean lead to weakening of trade wind due to low-level divergence and westerly anomaly. AM6 does not show such low-level wind anomaly that is a favorable condition for forming double-ITCZ, but CM6NOS does. CM6NOS shows a low-level convergence anomaly south of the convective zones in $\mathrm{Pa}$ cific and Atlantic, resulting in a double ITCZ in precipitation, as shown in the following section.

\subsubsection{Precipitation Bias}

As pointed out by Li et al. (2020), the low-level surface wind divergence anomalies in CM6NOS might generate apparent moist and warm air advection in the trade wind regions although the mean low-level flows continue to be easterly (Fig. 5a). That is, weaker transport of relatively cold and dry air owing to the westerly wind differences between two groups of models with FIREs and without FIREs, resulting in biased high precipitation in CM6NOS (Fig. 6f) than in CM6SON (Fig. 6g) over the trade wind regions. There is biased high precipitation in the TWP of AM6NOS (Fig. 6b), which is reduced in AM6SON (Fig. 6c), in particular over SPCZ (Fig. 6d). Figures 6i - k show the difference of the absolute bias between AM6 and CM6, AM6NOS and CM6NOS and AM6SON and CM6SON. The two CM6 groups show larger excessive bias than AM6 groups over the trade wind regions, indicating weaker easterlies, although the bi- ases in CMIP6 are larger in magnitude than those in AMIP6 counterparts for NOS, SON, and all-model MMMs. This result suggest that interactive ocean does not improve the precipitation simulations except over the northwest Pacific, SPCZ, and west Atlantic. The differences in precipitation absolute biases between the NOS and SON groups of models have rather different spatial patterns between AMIP6 and CMIP6 (Figs. 6d and h); i.e., improvements occur over the TWP and SPCZ for AMIP6 but the subtropics for CMIP6. This result suggests that the impact of interactive ocean resulted from the inclusion of FIREs is through the stronger changes in low-level circulation, which results in large changes in precipitation over the subtropics. Without interactive ocean, the high biased precipitation in AM6NOS (Fig. 6b) is reduced in AM6SON (Fig. 6c) over the TWP and SPCZ (Fig. 6d).

\subsection{Summary of Results by Taylor Diagram and Absolute Bias Ranking}

The Taylor diagram (Taylor 2001) can summarize the information on spatial patterns using the spatial correlation with observations and normalized standard deviation. Li et al. (2020) found significant improvements from CM6NOS to CM6SON and from CMIP5 to CMIP6 due to more models with the inclusion of FIREs in CMIP6.

Figures 7 and 8 show the Taylor diagrams for RLUT, RSUT, RSDS, and precipitation. CM6SON group (symbols with open blue circle in Figs. 7c, d, and 8c) has higher correlation and normalized standard deviation closer to 1 than CM6NOS (blue "+") for radiation fields and precipitation (Fig. 8d). However, the impacts of FIREs do not show similar 

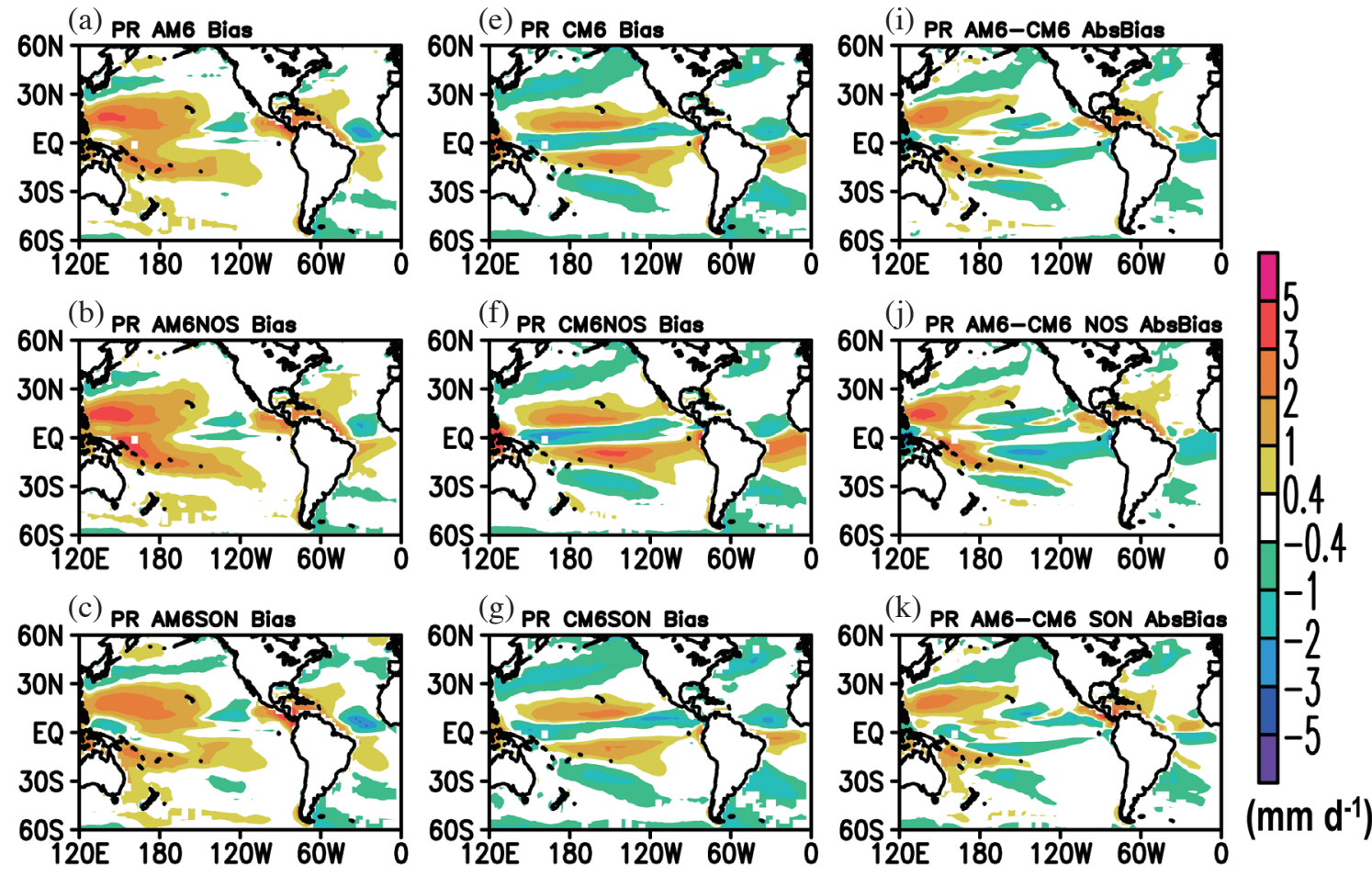

(d) PR AM6(NOS-SON) absBias
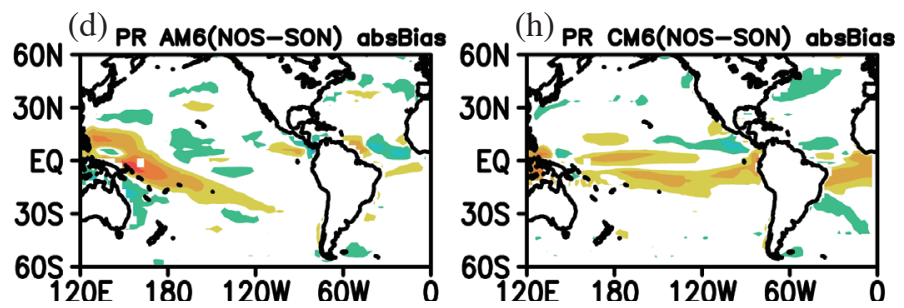

Fig. 6. Same as Fig. 4 but for precipitation $\left(\mathrm{mm} \mathrm{d}^{-1}\right)$ against GPCP. 

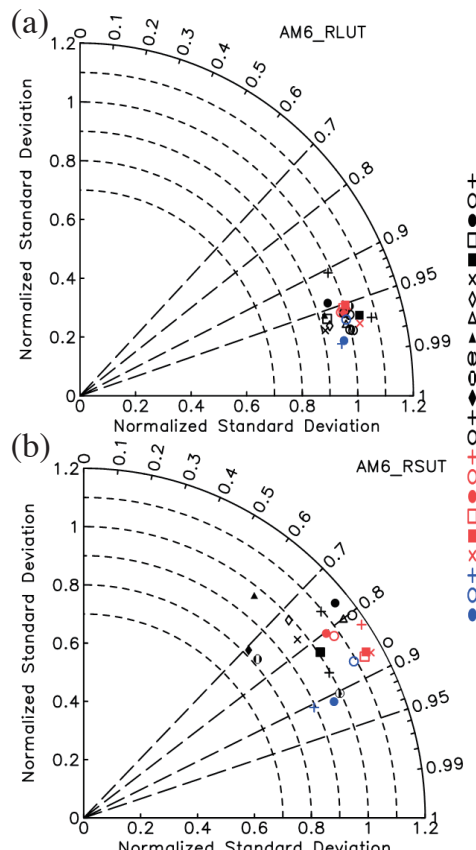

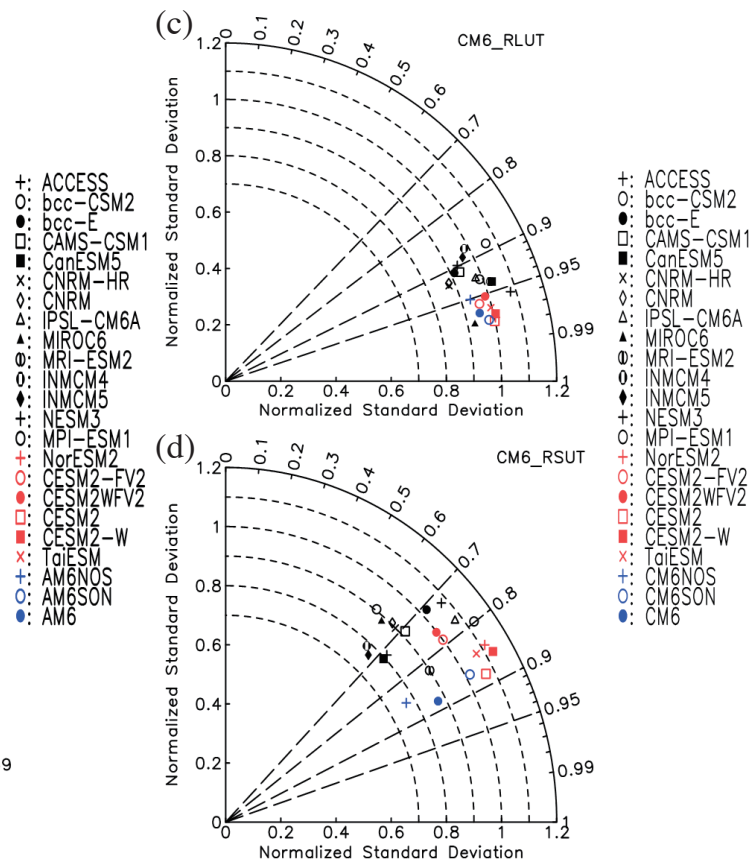

Fig. 7. (a) Taylor diagram showing the normalized standard deviation of oceanic $\left(60^{\circ} \mathrm{N}-60^{\circ} \mathrm{S}\right)$ outgoing longwave radiation $\left(\mathrm{RLUT}\right.$ : W $\left.\mathrm{m}^{-2}\right)$ and correlation with CERES for each model (see the legend listed on the right). Different colors represent models without falling ice radiative effects (FIREs) (black), with FIREs using MG1 or MG2 (red), and multi-model means (MMMs) for different groups and subgroups of AMIP6 (AM6) MMM (blue). Same as (a) but for CMIP5. (c) same as (a) but for reflected shortwave radiation (RSUT), (d) same as (b) but for CMIP6. See Table 1 for the model acronyms and CMIP6 model groups and subgroups.

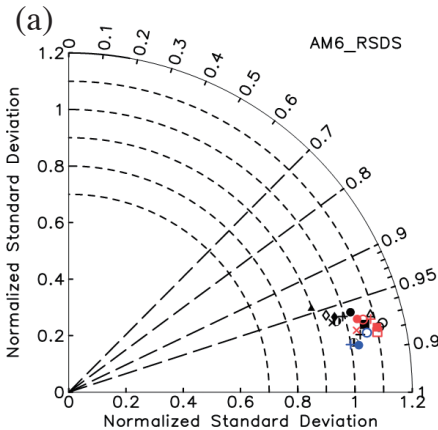

(b)

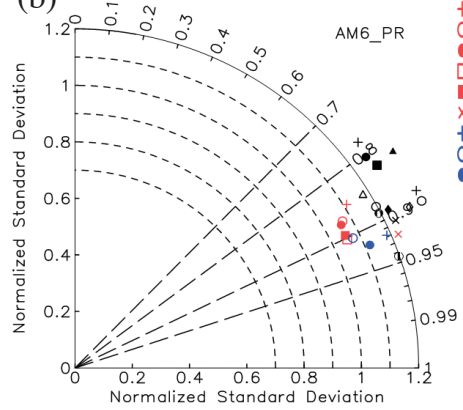

(c)

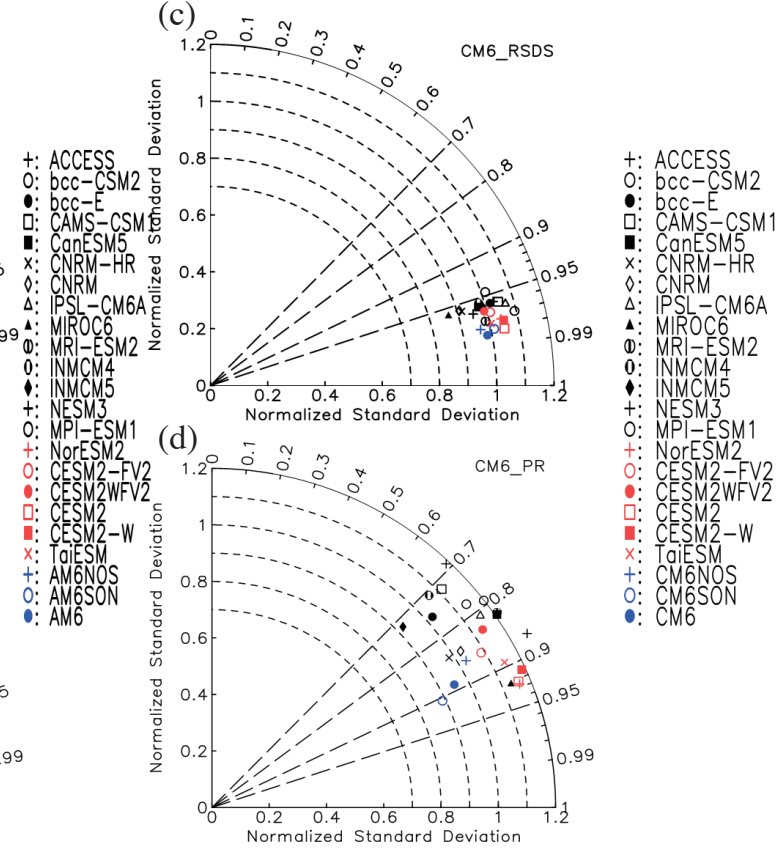

Fig. 8. (a) Taylor diagram showing the normalized standard deviation of oceanic $\left(60^{\circ} \mathrm{N}-60^{\circ} \mathrm{S}\right)$ surface downward shortwave radiation (RSDS: $\mathrm{W} \mathrm{m}^{-2}$ ) and correlation with CERES for each model (see the legend listed on the right). Different colors represent models without falling ice radiative effects (FIREs) (black), with FIREs using MG1 or MG2 (red), and multi-model means (MMMs) for different groups and subgroups of AMIP6 (AM6) MMM (blue). (b) same as (a) but for CMIP5. (c) same as (a) but for surface precipitation (PR: mm day ${ }^{-1}$ ) against GPCP. (d) same as (b) but for CMIP6. See Table 1 for the model acronyms and CMIP6 model groups and subgroups. 
performance improvements from AM6NOS to AM6SON for RLUT, RSUT, RSDS, and precipitation (Figs. 7a, b, 8a, b). In fact, the performance for AM6SON is even worse than AM6NOS in RLUT (Fig. 7a) and RSDS (Fig. 8a).

The model ranking of the absolute biases can be found in Fig. 9 for RLUT, RSUT, RSDS, and precipitation in AMIP6 and CMIP6, respectively. The results show that the best performers belong to several CMIP6 models with SON (red color bar) and subgroup CM6SON (dark bar) than models without FIREs (blue colored bar) for RLUT (Fig. 9e), for RSUT (Fig. 9f), for RSDS (Fig. 9g), and for precipitation (Fig. 9h). The outperformance in CM6SON compared to CM6NOS is not seen in the AMIP6 models (Figs. 9a-d). As can be seen in AM6, the absolute bias in AM6NOS are even better than their AM6SON counterpart for RLUT (Fig. 9a), RSUT (Fig. 9b), RSDS (Fig. 9c), and precipitation (Fig. 9d). The constraint of prescribed SSTs might be responsible for the inconsistent FIREs impacts in AMIP6, compared to CMIP6.

The above-mentioned results imply that there are nontrivial impacts of FIREs on CMIP6 and these impacts contribute to the improvement from CM6NOS to CM6SON. These results also suggest that the role of interactive ocean is important for the inclusion of the FIREs and the feedback from ocean is a critical for reducing systematic regional errors against observations (Michibata et al. 2019; Li et al. 2020). The systematic impact of FIREs on low-level circulation mainly occurs over tropical deep convection and heavy precipitating regions, as well as the trade wind regions, which are not found in the uncoupled AMIP6 simulations.

\section{SUMMARY AND DISCUSSION}

In this study, we have quantified the impacts of FIREs on ice water path, radiation budget, low-level winds and precipitation between two sets of outputs, one from uncoupled AMIP6 with prescribed SSTs and the other from the fully-coupled CMIP6 in historical scenario using the same models. We compared two groups of models, composing of 14 models without the inclusion FIREs (NOS) and 6 models with the inclusion of FIREs (SON). Comparison of AMIP6 with CMIP6 can identify the influences of interactive ocean and ocean circulations.

For no FIREs included in AM6NOS and CM6NOS, the overestimated biases of upward longwave radiative flux at TOA (RLUT) are found over the convective regions. The AM6NOS and CM6NOS show underestimates of RLUT of 4 - $20 \mathrm{~W} \mathrm{~m}^{-2}$, overestimated reflected shortwave

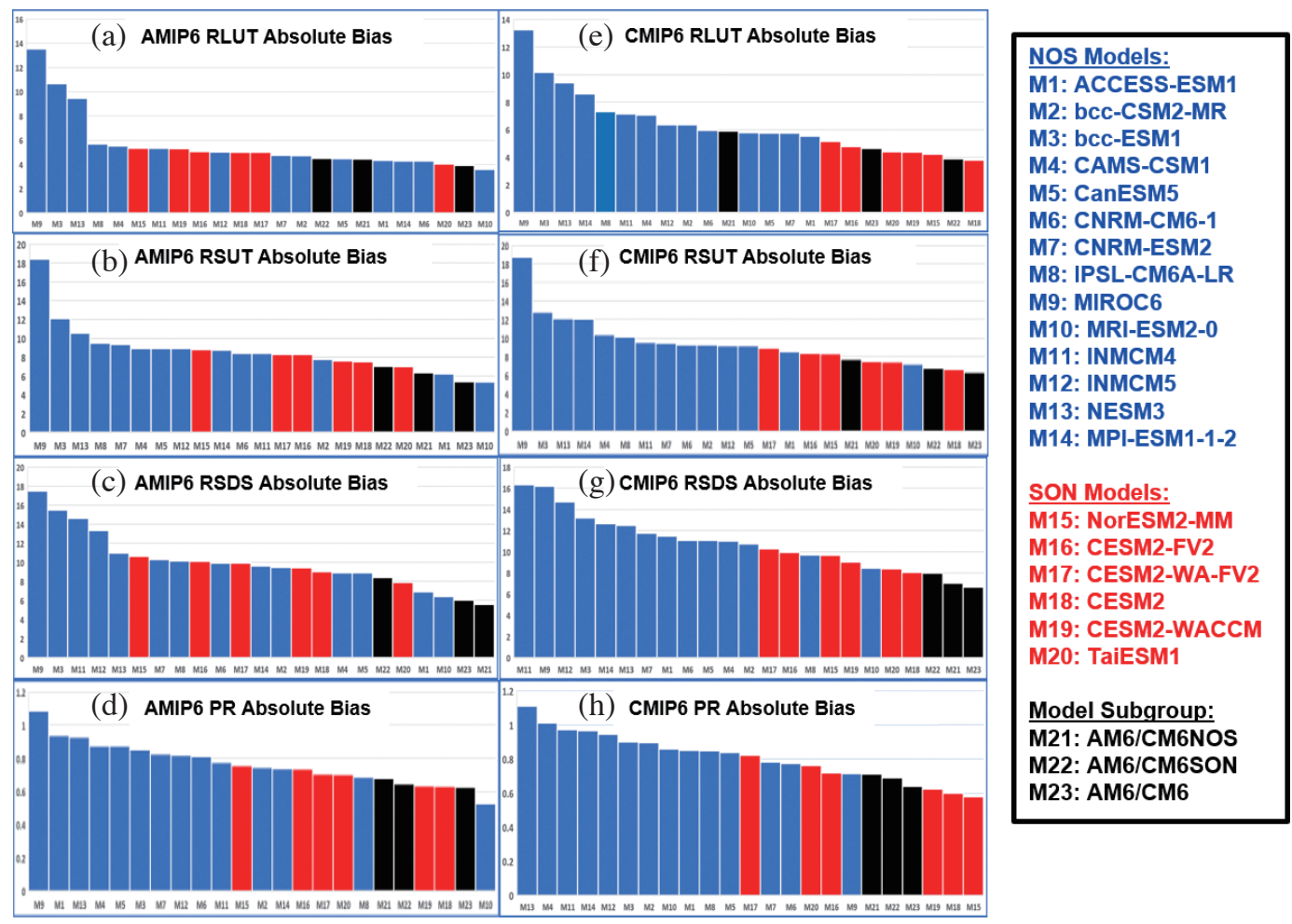

Fig. 9. (a) The ranking of absolute bias of outgoing longwave radiation (RLUT: $\mathrm{W} \mathrm{m}^{-2}$ ) at top pf atmosphere (TOA) against CERES for each AMIP6 model (1) - (20), (21) NOS group multi-model-mean (MMM) and its members (black colored bars), (22) SON subgroup MMM and its members (red colored bars), and (23) AMIP5 MMM (AM6). The reference data is CERES for ocean-only latitude belts of $60^{\circ} \mathrm{N}-60^{\circ} \mathrm{S}$. (b) same as (a) but for reflected shortwave radiation (RSUT). (c) same as (a) but for surface downward shortwave radiation (RSDS). (d) same as (a) but for surface precipitation (PR: mm day ${ }^{-1}$ ) against GPCP. (e) - (h) same as (a) - (d) but for CMIP6. The annual time average is over 1980 - 2014. Table 1 and name list on the right is for the model acronyms, groups and subgroups. 
at the top of the atmosphere (RSUT) and underestimates of downward shortwave at the surface (RSDS) with values of $16-20 \mathrm{~W} \mathrm{~m}^{-2}$ over most of the trade wind regions in Pacific and Atlantic oceans. Their values of the biases are reduced to $4-8 \mathrm{~W} \mathrm{~m}^{-2}$ with FIREs included in both AM6SON and CM6SON over trade wind regions. The shortwave flux at the surface (RSDS) and the TOA upward shortwave flux (RSUT) are biased high by up to $4-20 \mathrm{~W} \mathrm{~m}^{-2}$, the biases are reduced for AM6SON and CM6SON by $4-8 \mathrm{~W} \mathrm{~m}^{-2}$. These reduced bias patterns are also consistent with overestimates of shortwave radiation at the surface (RSDS) and TOA (RSUT) found in CMIP3 and CMIP5 simulations and those found in the sensitivity experiments using NCARDOE CESM1-CAM5 (Li et al. 2015, 2016).

We found that there are substantial reductions in magnitude of biases in radiation fields due to the inclusion of FIREs and interactive ocean. The spatial patterns in the absolute biases are sharply different from those due to FIREs in either AMIP6 or CMIP6, with more significant improvements in the convective zones and the subtropics of CMIP6 than in AMIP6. These reduced bias patterns are also consistent with overestimates of shortwave radiation at the surface (RSDS) and TOA (RSUT) found in CMIP3 and CMIP5 simulations and those found in the sensitivity experiments using NCAR-DOE CESM1-CAM5 (Li et al. 2015, 2016). On the other hand, the spatial patterns due to interactive ocean are rather similar, with improvements over the northwest and southeast Pacific, TWP and SPCZ.

We found that the annual mean surface winds biases at $1000 \mathrm{hPa}$ in CMIP6 models with the exclusion of FIREs are more westerly over most of the trade wind regions and meridional divergence anomalies along the convective zones in Pacific and Atlantic compared to those with FIREs. This implies for weaker easterlies and meridional divergent flows along convective zones into the trade wind regions without FIREs. The biases of surface winds are reduced over most of the Pacific Ocean with the inclusion of FIREs. The weakening of low-level trade winds might generate a weaker transport of relatively cold and dry air, resulting in moister and warmer surface air and enhanced precipitation into the trade wind regions as well as the regions between Pacific ITCZ and SPCZ and north of ITCZ, as reported in Li et al. (2020). The weakening low-level winds also produce biased high surface precipitation found over the maximum low-level wind convergence south of ITCZ.

The inclusion of FIREs in AMIP6 has more or less similar magnitudes of impact to radiation fields compared to that in CMIP6, but it does not show a similar systematic change on local circulation and precipitation as seen in the CMIP6 counterpart. The impact of FIREs is most pronounced in ITCZ and the subtropical trade-wind regions in CMIP6 but over the tropical western Pacific and SPCZ in AMIP6. The differences in the radiation and precipitation biases between the AMIP6 and CMIP6 with FIREs are smaller in magnitude than between the AMIP6 and CMIP6 without FIREs but similar in the spatial patterns, implying that interactive ocean could overcompensate for missing an important physical process in models.

Given that the spatial pattern and magnitude of the impact are similar to those found in the observationally-based study of Waliser et al. (2011), a single climate model study of Li et al. (2014a), and multiple CMIP5 and CMIP6 mode study of Li et al. (2020), these consistent results suggest that there is a robust signal among GCMs in coupled GCMs. Overall, the results imply that neglecting the FIREs in a GCM can produce regional impacts on the surface and top of atmosphere radiation fluxes of a similar magnitude to the model systematic errors when compared to observations. The important point in this study is that the magnitude of the impact of FIREs is of a similar order of magnitude to many of the regional biases in weather forecast and climate models and it should therefore be considered in the context of reducing compensating errors.

This study concludes that the falling ice (part of the ice water path) has non-negligible radiative effects relative to typical model errors in the current state-of-the-art GCMs, and FIREs should be included in all GCMs for improving the fidelity of model physical interactions in particular for fully coupled models. The important role of falling ice in the climate system is critically important for improving the model representation that treats the radiative effect of hydrometeors to better characterize the atmospheric radiative transfer and the associated local circulations. We also found that the circulation changes due to FIREs are very different between AMIP6 and CMIP6. The sensitivity of FIREs is stronger in the trade wind regions in CMIP6 than in AMIP6 due to the influence of interactive ocean, suggesting that cautious are needed to be taken when testing physical process representations in uncoupled models over tropical and subtropical oceans. This conclusion is also supported by systematic improvements in groups of models with the inclusion of FIREs than the exclusion of FIREs, hinting the important roles of FIREs in radiation-circulation coupling.

However, due to other sources of uncertainty and deficiencies in fully coupled climate models, we acknowledge that an improvement of this particular physical process in FIREs alone does not necessarily lead to better climate simulations. In fact, non-trivial biases are still found in CMIP6 models even they are improved with the inclusion of FIREs compared to those without. Further work is required to understand the cause to reduce the biases found in this study with FIREs included.

Acknowledgements The contributions by JLL to this study were carried out on behalf of the Jet Propulsion Laboratory, California Institute of Technology, with the National Aeronautics and Space Administration (NASA). The availability of vertically-resolved cloud hydrometeor profiles 
2C-ICE (Deng et al. 2010, 2013) is derived from CloudSat (Stephens et al. 2008; Austin et al. 2009). The CERES Energy Balanced and Filled (CERES-EBAF) data provides radiation at TOA and corresponding surface flux radiation products constrained by TOA CERES-EBAF adjustments. The GPCP Version 2.3 Combined monthly Precipitation Data Set, ranges from Jan 1979 through May 2019 is used (https://www.esrl.noaa.gov/psd/). The QuikSCAT sea-surface wind speed and direction data under all weather and cloud conditions over Earth's oceans ranges from August 1999 to October 2009 (http://podaac-www.jpl.nasa.gov/) for the obs4MIPS project.

\section{REFERENCES}

Adler, R. F., G. J. Huffman, A. Chang, R. Ferraro, P.-P. Xie, J. Janowiak, B. Rudolf, U. Schneider, S. Curtis, D. Bolvin, A. Gruber, J. Susskind, P. Arkin, and E. Nelkin, 2003: The version-2 global precipitation climatology project (GPCP) monthly precipitation analysis (1979-present). J. Hydrometeorol., 4, 1147-1167, doi: 10.1175/1525-7541(2003)004<1147:TVGPCP>2 . 0.CO;2. [Link]

Adler, R. F., M. R. P. Sapiano, G. J. Huffman, J.-J. Wang, G. Gu, D. Bolvin, L. Chiu, U. Schneider, A. Becker, E. Nelkin, P. Xie, R. Ferraro, and D.-B. Shin, 2018: The Global Precipitation Climatology Project (GPCP) Monthly Analysis (New Version 2.3) and a Review of 2017 Global Precipitation. Atmosphere, 9, 138, doi: 10.3390/atmos9040138. [Link]

Austin, R. T., A. J. Heymsfield, and G. L. Stephens, 2009: Retrieval of ice cloud microphysical parameters using the CloudSat millimeter-wave radar and temperature. J. Geophys. Res., 114, D00A23, doi: 10.1029/2008JD010049. [Link]

Copernicus Climate Change Service (C3S), 2017: ERA5: Fifth generation of ECMWF atmospheric reanalyses of the global climate. Copernicus Climate Change Service Climate Data Store (CDS). Available at https:// cds.climate.copernicus.eu/cdsapp\#!/home.

Deng, M., G. G. Mace, Z. Wang, and H. Okamoto, 2010: Tropical Composition, Cloud and Climate Coupling Experiment validation for cirrus cloud profiling retrieval using CloudSat radar and CALIPSO lidar. J. Geophys. Res., 115, D00J15, doi: 10.1029/2009JD013104. [Link]

Deng, M., G. G. Mace, Z. Wang, and R. P. Lawson, 2013: Evaluation of several A-Train ice cloud retrieval products with in situ measurements collected during the SPARTICUS campaign. J. Appl. Meteorol. Climatol., 52, 1014-1030, doi: 10.1175/JAMC-D-12-054.1. [Link]

De Szoeke, S. P. and S.-P. Xie, 2008: The tropical eastern Pacific seasonal cycle: Assessment of errors and mech- anisms in IPCC AR4 coupled ocean-atmosphere general circulation models. J. Clim., 21, 2573-2590, doi: 10.1175/2007jcli1975.1. [Link]

Eyring, V., S. Bony, G. A. Meehl, C. A. Senior, B. Stevens, R. J. Stouffer, and K. E. Taylor, 2016: Overview of the Coupled Model Intercomparison Project Phase 6 (CMIP6) experimental design and organization. Geosci. Model Dev., 9, 1937-1958, doi: 10.5194/gmd-91937-2016. [Link]

Forbes, R. M., A. M. Tompkins, and A. Untch, 2011: A new prognostic bulk microphysics scheme for the IFS. Technical Memorandum No. 649, ECMWF. Available at https://www.ecmwf.int/en/publications.

Gettelman, A. and H. Morrison, 2015: Advanced two-moment bulk microphysics for global models. Part I: Offline tests and comparison with other schemes. J. Clim., 28, 1268-1287, doi: 10.1175/JCLI-D-14-00102.1. [Link]

Gettelman, A., X. Liu, S. J. Ghan, H. Morrison, S. Park, A. J. Conley, S. A. Klein, J. Boyle, D. L. Mitchell, and J.L.F. Li, 2010: Global simulations of ice nucleation and ice supersaturation with an improved cloud scheme in the Community Atmosphere Model. J. Geophys. Res., 115, D18216, doi: 10.1029/2009JD013797. [Link]

Hersbach,H. and D. Dee, 2016: ERA5 reanalysis is in production. ECMWF Newsletter 147, ECMWF. Available at https://www.ecmwf.int/en/newsletter/147/news/era5reanalysis-production (last access: 24 March 2017).

IPCC, 2007: Climate Change 2007: The Physical Science Basis, Contribution of Working Group I to the Fourth Assessment Report of the Intergovernmental Panel on Climate Change, Cambridge University Press, Cambridge, United Kingdom and New York, USA, 996 pp.

Kato, S., F. G. Rose, S. Sun-Mack, W. F. Miller, Y. Chen, D. A. Rutan, G. L. Stephens, N. G. Loeb, P. Minnis, B. A. Wielicki, D. M. Winker, T. P. Charlock, P. W. Stackhouse, K.-M. Xu, and W. D. Collins, 2011: Improvements of top-of-atmosphere and surface irradiance computations with CALIPSO-, CloudSat-, and MODIS-derived cloud and aerosol properties. J. Geophys. Res., 116, D19209, doi: 10.1029/2011JD016050. [Link]

Kato, S., N. G. Loeb, D. A. Rutan, F. G. Rose, S. Sun-Mack, W. F. Miller, and Y. Chen, 2012: Uncertainty estimate of surface irradiances computed with MODIS-, CALIPSO-, and CloudSat-derived cloud and aerosol properties. Surv. Geophys., 33, 395-412, doi: 10.1007/ s10712-012-9179-x. [Link]

Kato, S., N. G. Loeb, F. G. Rose, D. R. Doelling, D. A. Rutan, T. E. Caldwell, L. Yu, and R. A. Weller, 2013: Surface irradiances consistent with CERES-derived top-of-atmosphere shortwave and longwave irradiances. J. Clim., 26, 2719-2740, doi: 10.1175/JCLID-12-00436.1. [Link] 
Li, G. and S.-P. Xie, 2012: Origins of tropical-wide SST biases in CMIP multi-model ensembles. Geophys. Res. Lett., 39, L22703, doi: 10.1029/2012GL053777. [Link]

Li, G. and S.-P. Xie, 2014: Tropical Biases in CMIP5 Multimodel Ensemble: The Excessive Equatorial Pacific cold tongue and Double ITCZ Problems. J. Clim., 27, 1765-1780, doi: 10.1175/JCLI-D-13-00337.1. [Link]

Li, J.-L. F., D. E. Waliser, W. -T. Chen, B. Guan, T. Kubar, G. Stephens, H. -Y. Ma, M. Deng, L. Donner, C. Seman, and L. Horowitz, 2012: An observationally based evaluation of cloud ice water in CMIP3 and CMIP5 GCMs and contemporary reanalyses using contemporary satellite data. J. Geophys. Res., 117, doi: 10.1029/2012JD017640. [Link]

Li, J.-L. F., D. E. Waliser, G. Stephens, S. Lee, T. L'Ecuyer, S. Kato, N. Loeb, and H.-Y. Ma, 2013: Characterizing and understanding radiation budget biases in CMIP3/ CMIP5 GCMs, contemporary GCM, and reanalysis. J. Geophys. Res., 118, 8166-8184, doi: 10.1002/ jgrd.50378. [Link]

Li, J.-L. F., W.-L. Lee, D. E. Waliser, J. D. Neelin, J. P. Stachnik, and T. Lee, 2014a: Cloud-precipitationradiation-dynamics interaction in global climate models: A snow and radiation interaction sensitivity experiment. J. Geophys. Res., 119, 3809-3824, doi: 10.1002/2013JD021038. [Link]

Li, J.-L. F., R. M. Forbes, D. E. Waliser, G. Stephens, and S. Lee, 2014b: Characterizing the radiative impacts of precipitating snow in the ECMWF Integrated Forecast System global model. J. Geophys. Res., 119, 96269637, doi: 10.1002/2014JD021450. [Link]

Li, J.-L. F., W.-L. Lee, T. Lee, E. Fetzer, J.-Y. Yu, T. L. Kubar, and C. Boening, 2015: The impacts of cloud snow radiative effects on Pacific Ocean surface heat fluxes, surface wind stress, and ocean temperatures in coupled GCM simulations. J. Geophys. Res., 120, 2242-2260, doi: 10.1002/2014JD022538. [Link]

Li, J.-L. F., W.-L. Lee, D. Waliser, Y.-H. Wang, J.-Y. Yu, X. Jiang, T.L'Ecuyer, Y.-C. Chen, T. Kubar, E. Fetzer, and M. Mahakur, 2016: Considering the radiative effects of snow on tropical Pacific Ocean radiative heating profiles in contemporary GCMs using A-Train observations. J. Geophys. Res., 121, 1621-1636, doi: 10.1002/2015JD023587. [Link]

Li, J.-L. F., K.-M. Xu, J. H. Jiang, W.-L. Lee, L.-C. Wang, J.-Y. Yu, G. Stephens, E. Fetzer, and Y.-H. Wang, 2020: An overview of CMIP5 and CMIP6 simulated cloud ice, radiation fields, surface wind stress, sea surface temperatures, and precipitation over tropical and subtropical oceans. J. Geophys. Res., 125, e2020JD032848, doi: 10.1029/2020JD032848. [Link]

Lin, J.-L., 2007: The double-ITCZ problem in IPCC AR4 coupled GCMs: Ocean-atmosphere feedback analysis. J. Clim., 20, 4497-4525, doi: 10.1175/jcli4272.1.
[Link]

Loeb, N. G., B. A. Wielicki, D. R. Doelling, G. L. Smith, D. F. Keyes, S. Kato, N. Manalo-Smith, and T. Wong, 2009: Toward optimal closure of the Earth's top-of-atmosphere radiation budget. J. Clim., 22, 748-766, doi: 10.1175/2008jcli2637.1. [Link]

Loeb, N. G., J. M. Lyman, G. C. Johnson, R. P. Allan, D. R. Doelling, T. Wong, B. J. Soden, and G. L. Stephens, 2012: Observed changes in top-of-the-atmosphere radiation and upper-ocean heating consistent within uncertainty. Nat. Geosci., 5, 110-113, doi: 10.1038/ NGEO1375. [Link]

Meehl, G. A., C. Covey, B. McAvaney, M. Latif, and R. J. Stouffer, 2005: Overview of the Coupled Model Intercomparison Project. Bull. Amer. Meteorol. Soc., 86, 89-93.

Michibata, T., K. Suzuki, M. Sekiguchi, and T. Takemura, 2019: Prognostic Precipitation in the MIROC6SPRINTARS GCM: Description and Evaluation Against Satellite Observations. J. Adv. Model. Earth Syst., 11, 839-860, doi: 10.1029/2018MS001596. [Link]

Randall,D.A., R. A. Wood, S. Bony, R. Colman, T. Fichefet, J. Fyfe, V. Kattsov, A. Pitman, J. Shukla, J. Srinivasan, R.J. Stouffer, A. Sumi, and K.E. Taylor, 2007: Climate models and their evaluation. In: Solomon, S., D. Qin, M. Manning, Z. Chen, M. Marquis, K. B. Averyt, M. Tignor, and H. L. Miller (Eds.), Climate Change 2007: The Physical Science Basis, Contribution of Working Group I to the Fourth Assessment Report of the Intergovernmental Panel on Climate Change, Cambridge University Press, Cambridge, United Kingdom and New York, USA, 589-662.

Stephens, G. L., 2005: Cloud feedbacks in the climate system: A critical review. J. Clim., 18, 237-273, doi: 10.1175/jcli-3243.1. [Link]

Stephens, G. L., D. G. Vane, S. Tanelli, E. Im, S. Durden, M. Rokey, D. Reinke, P. Partain, G. G. Mace, R. Austin, T. L'Ecuyer, J. Haynes, M. Lebsock, K. Suzuki, D. Waliser, D. Wu, J. Kay, A. Gettelman, Z. Wang, and R. Marchand, 2008: CloudSat mission: Performance and early science after the first year of operation. J. Geophys.Res., 113, D00A18, doi: 10.1029/2008JD009982. [Link]

Taylor, K. E., 2001: Summarizing multiple aspects of model performance in a single diagram. J. Geophys. Res., 106, 7183-7192, doi: 10.1029/2000jd900719. [Link]

Taylor, K. E., R. J. Stouffer, and G. A. Meehl, 2012: An overview of CMIP5 and the experiment design. Bull. Amer. Meteorol. Soc., 93, 485-498, doi: 10.1175/ BAMS-D-11-00094.1. [Link]

Urraca, R., T. Huld, A. Gracia-Amillo, F. J. Martinez-dePison, F. Kaspar, and A. Sanz-Garcia, 2018: Evaluation of global horizontal irradiance estimates from 
ERA5 and COSMO-REA6 reanalyses using ground and satellite-based data. Sol. Energy, 164, 339-354, doi: 10.1016/j.solener.2018.02.059. [Link]

Waliser, D. E., J-L. F. Li, C. P. Woods, R. T. Austin, J. Bacmeister, J. Chern, A. Del Genio, J. H. Jiang, Z. Kuang, H. Meng, P. Minnis, S. Platnick, W. B. Rossow, G. L. Stephens, S. Sun-Mack, W.-K. Tao, A. M. Tompkins, D. G. Vane, C. Walker, and D. Wu, 2009: Cloud ice:
A climate model challenge with signs and expectations of progress. J. Geophys. Res., 114, D00A21, doi: 10.1029/2008JD010015. [Link]

Waliser, D. E., J.-L. F. Li, T. S. L'Ecuyer, and W.-T. Chen, 2011: The impact of precipitating ice and snow on the radiation balance in global climate models. Geophys. Res. Lett., 38, L06802, doi: 10.1029/2010GL046478. [Link]

\section{APPENDIX}
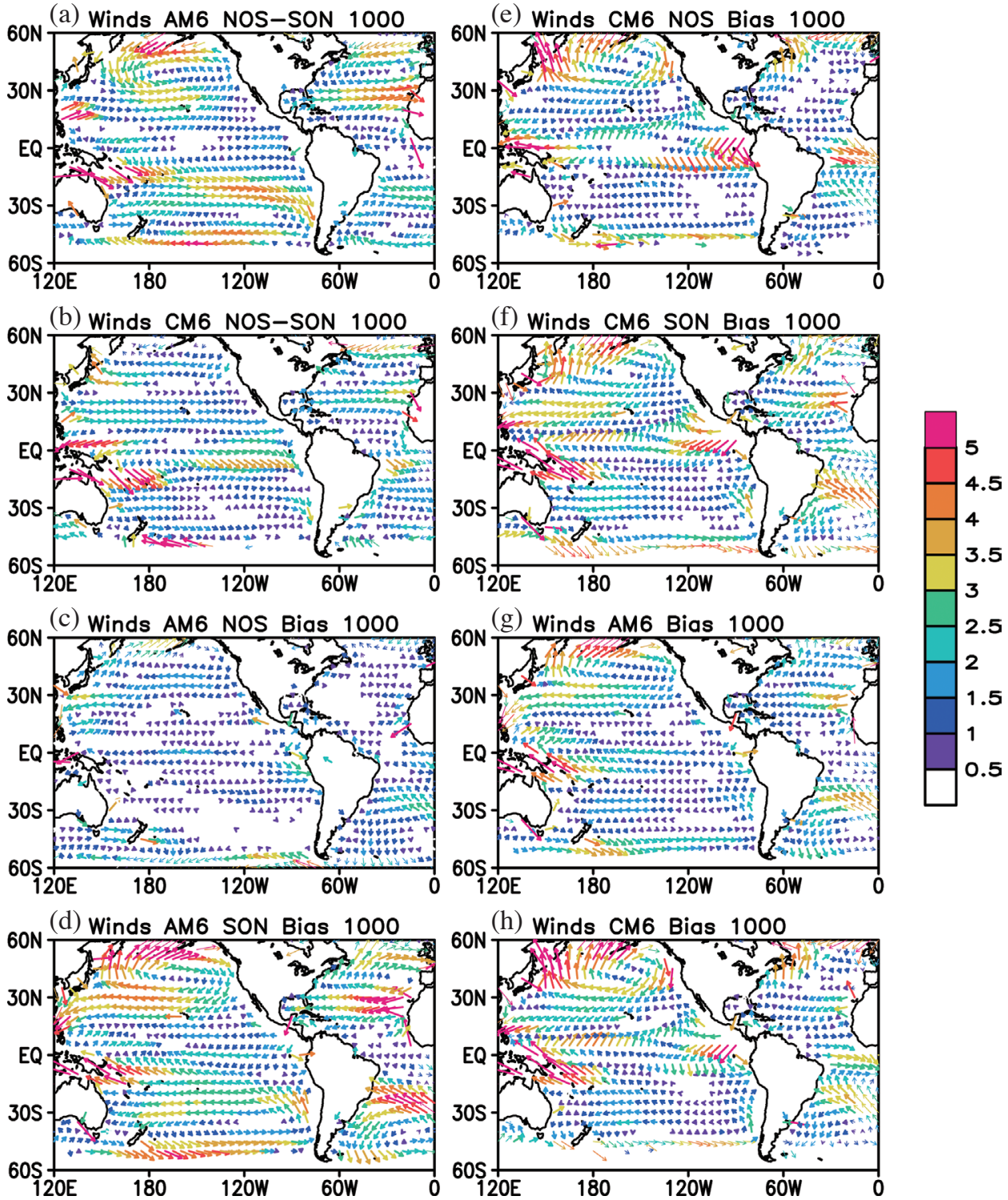

Fig. A1. (a) Annual mean ERA5 winds at $1000 \mathrm{hPa}$,(b)Time-averaged bias of AMIP6 (AM6) for the winds versus ERA5 at $1000 \mathrm{hPa}$, (c) same as (b) but for CMIP6 (CM6). (d) same as (c) but the difference of AMIP6 and CMIP6 (AM6-CM6). The annual time averaged is over 1980 - 2014. 

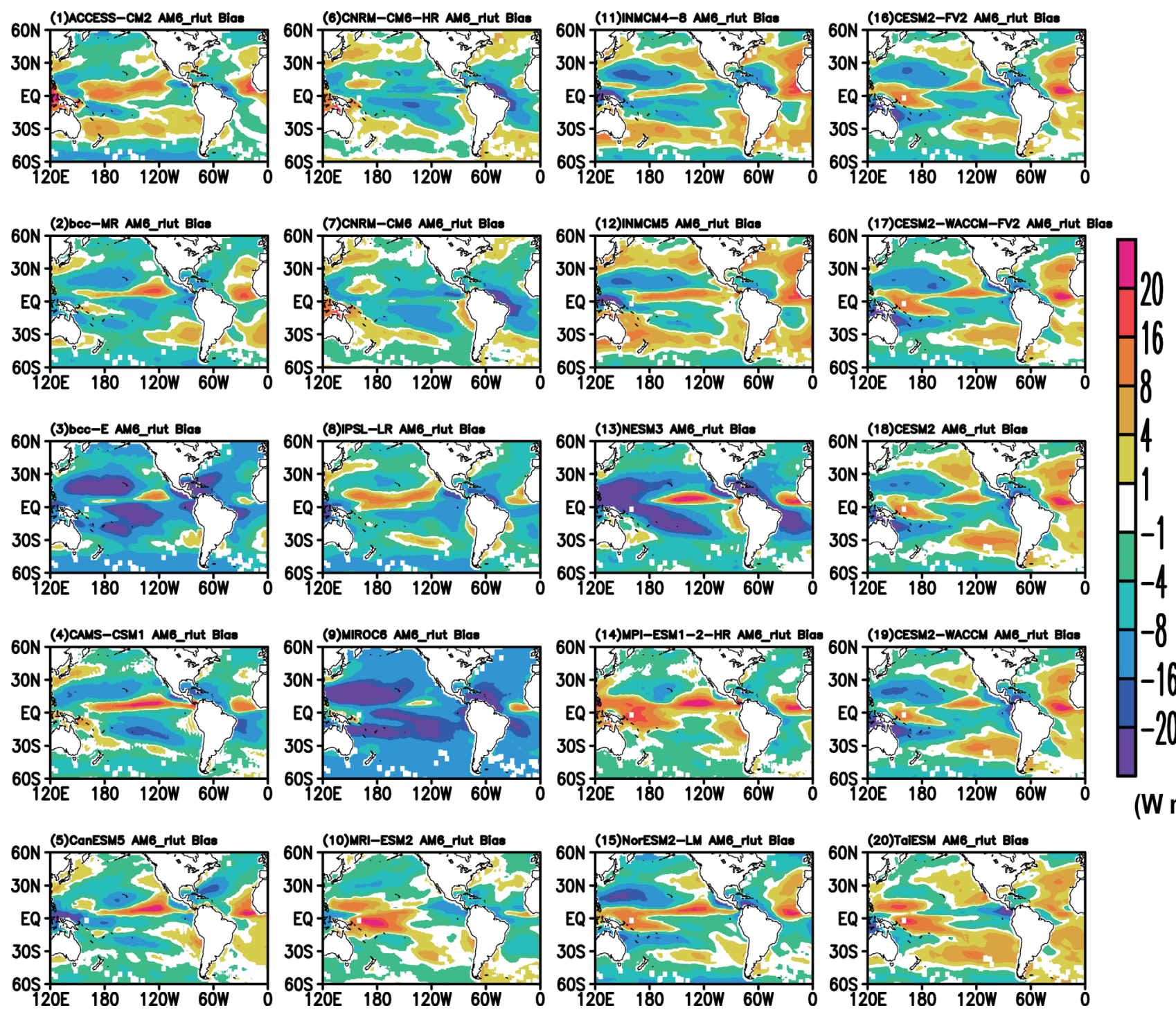

Fig. A2. Annual mean bias of AMIP6 in outgoing longwave radiation (RLUT: W m²) against CERES for models of (1) ACCESS, (2) bcc-CESM2, (3) bcc-E, (4) CAMS-CSM1, (5) CanESM5, (6) CNRM-HR, (7) CNRM, (8) IPSL-CM6A, (9) MIROC6, (10) MRI-ESM2, (11) INM-CM5, (12) INM-CM5, (13) NESM3, (14) MPI-ESM1, (15) NorESM2, (16) CESM2-FV2, (17) CESM2-WACCM-FV2, (18) CESM2, (19) CESM2-WACCM, (20) TaiESM. The annual time averaged over $2001-2014$. 

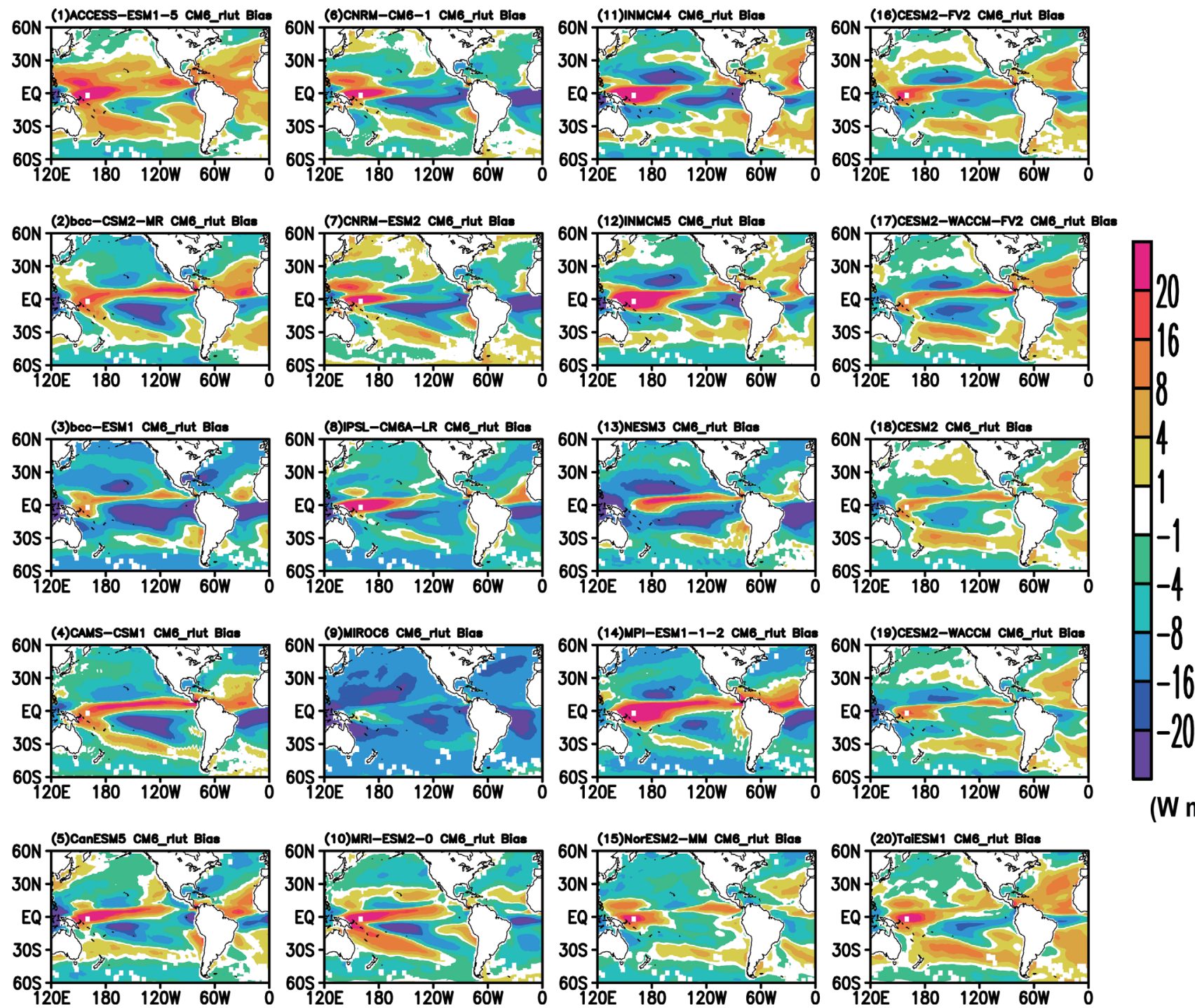

$\left(\mathrm{W} \mathrm{m}^{-2}\right)$

Fig. A3. Same as Fig. A2 but for CMIP6. 

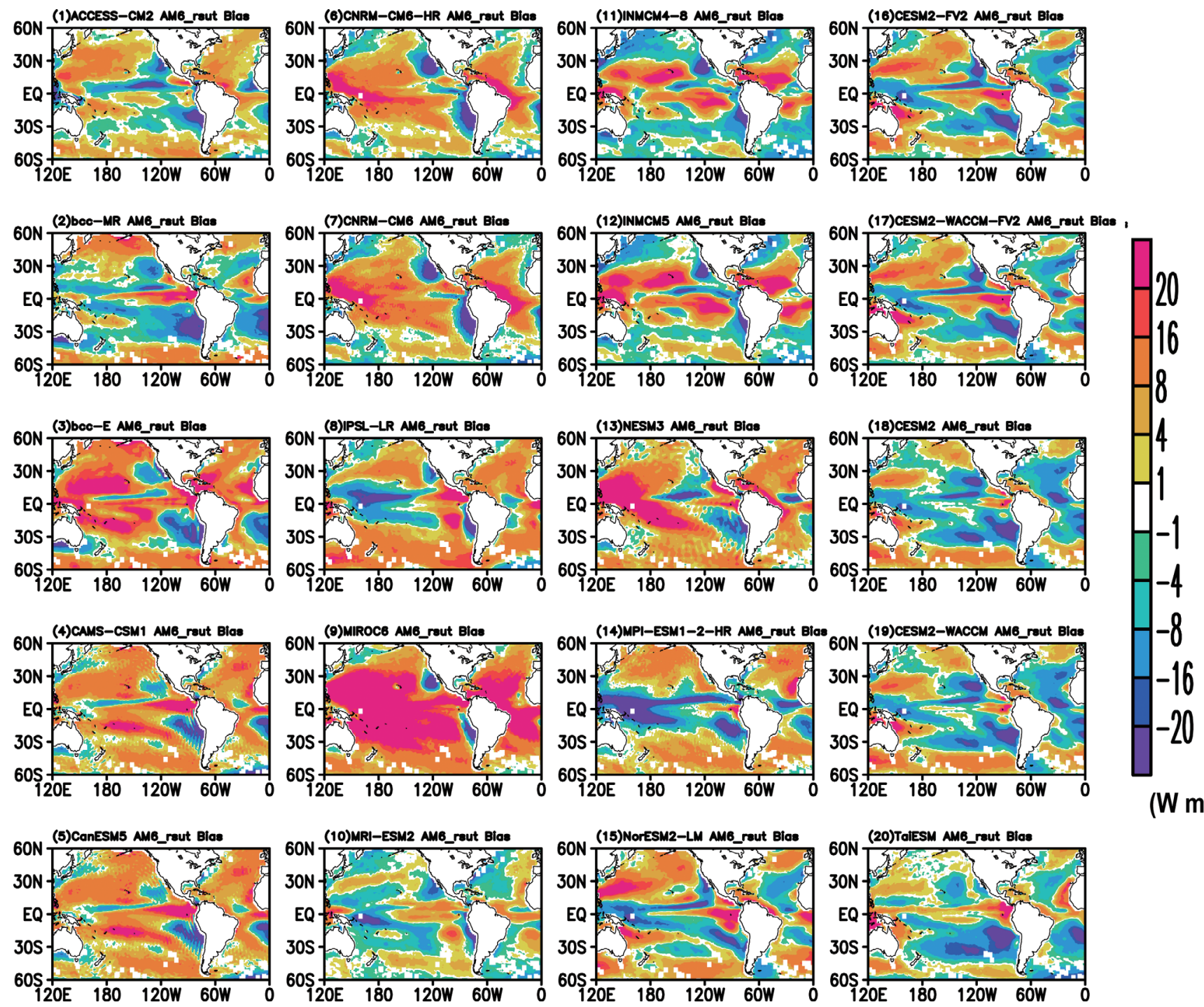

(W m-2)

Fig. A4. Same as Fig. A2 but for reflected shortwave radiation at top of atmosphere (TOA). 

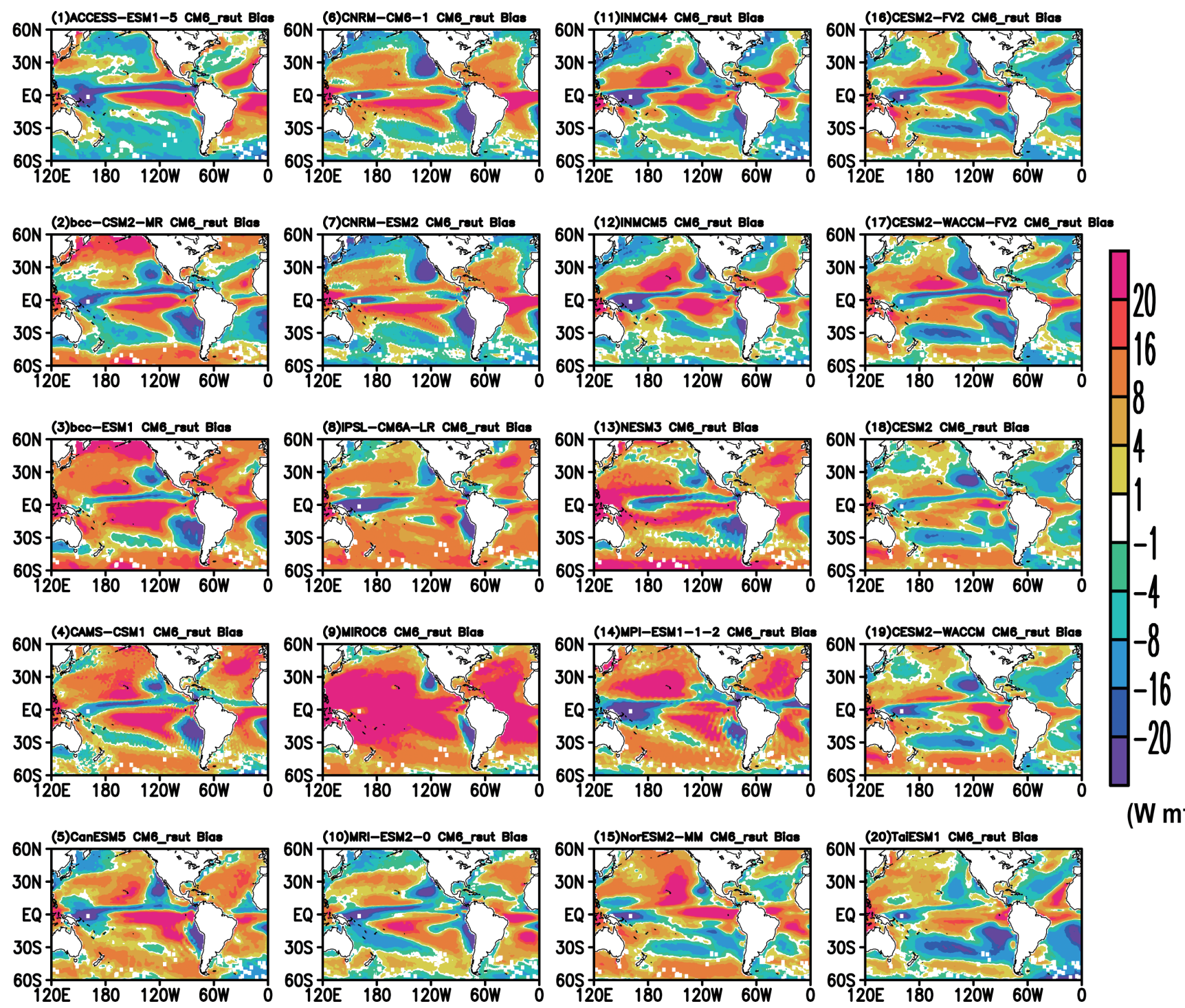

$\left(\mathrm{W} \mathrm{m}^{-2}\right)$

Fig. A5. Same as Fig. A4 but for CMIP6. 

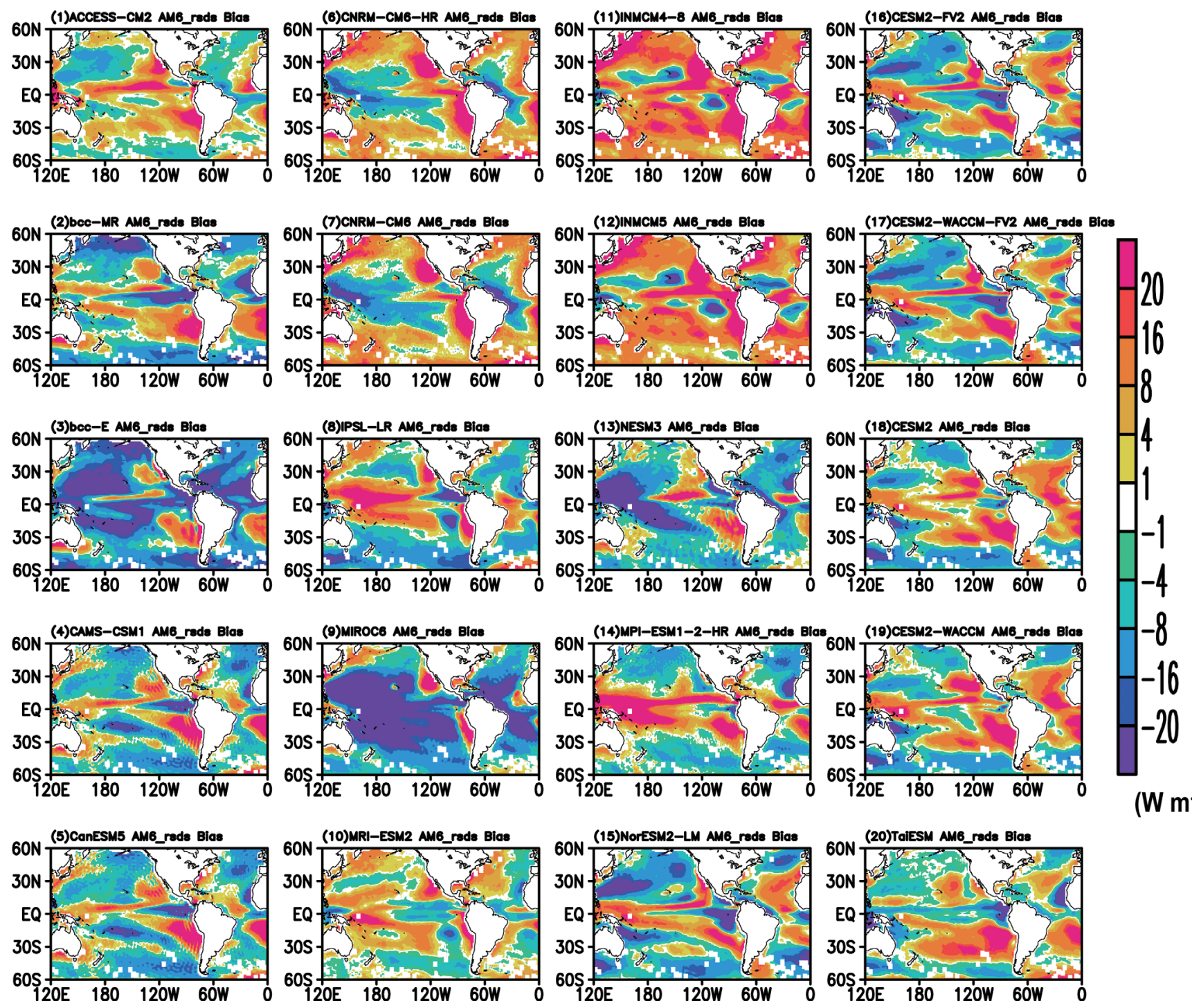

$\left(\mathrm{W} \mathrm{m}^{-2}\right)$

Fig. A6. Same as Fig. A2 but for surface downward shortwave radiation (RSDS). 

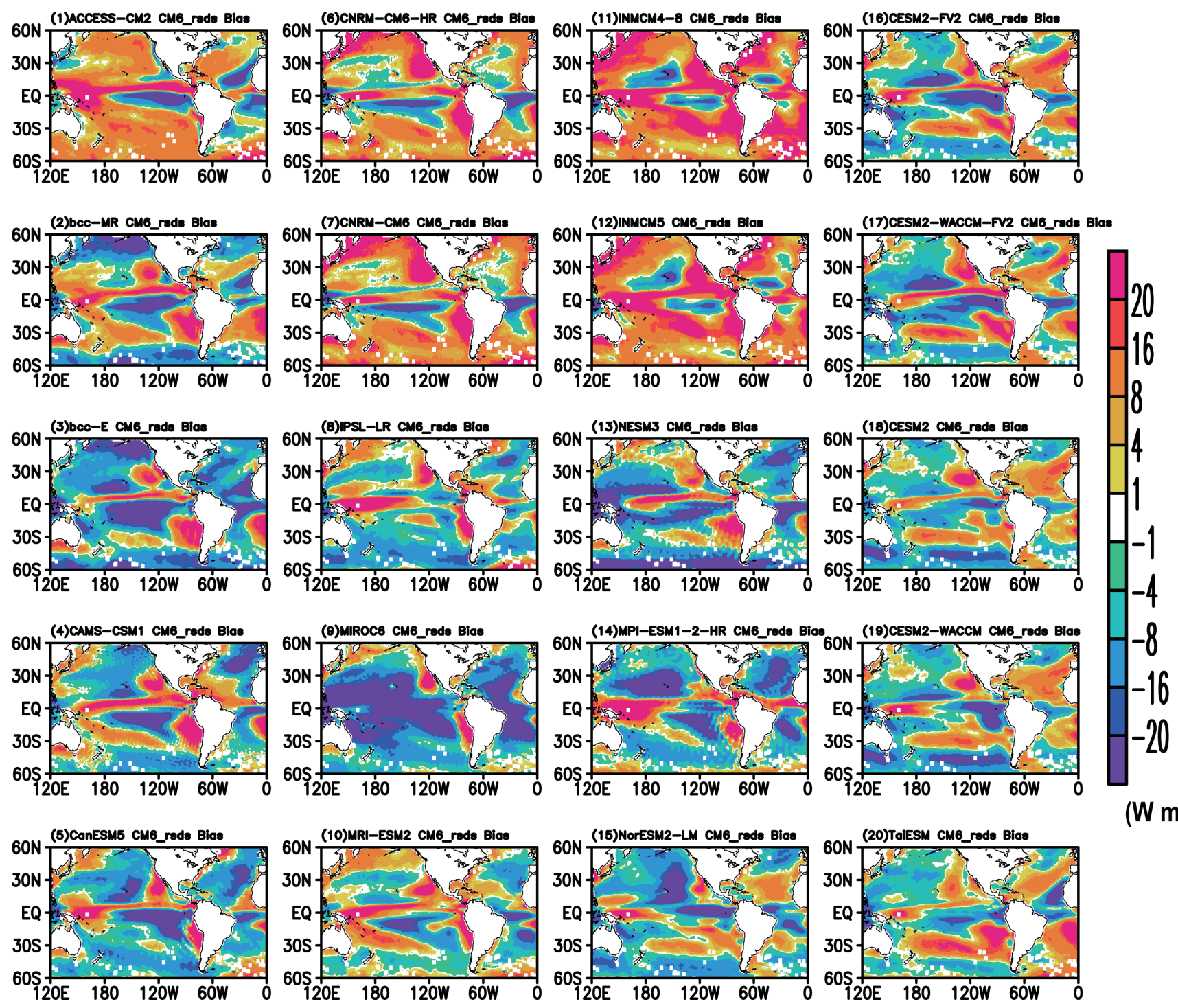

(W m ${ }^{-2}$ )

Fig. A7. Same as Fig. A4 but for CMIP6. 

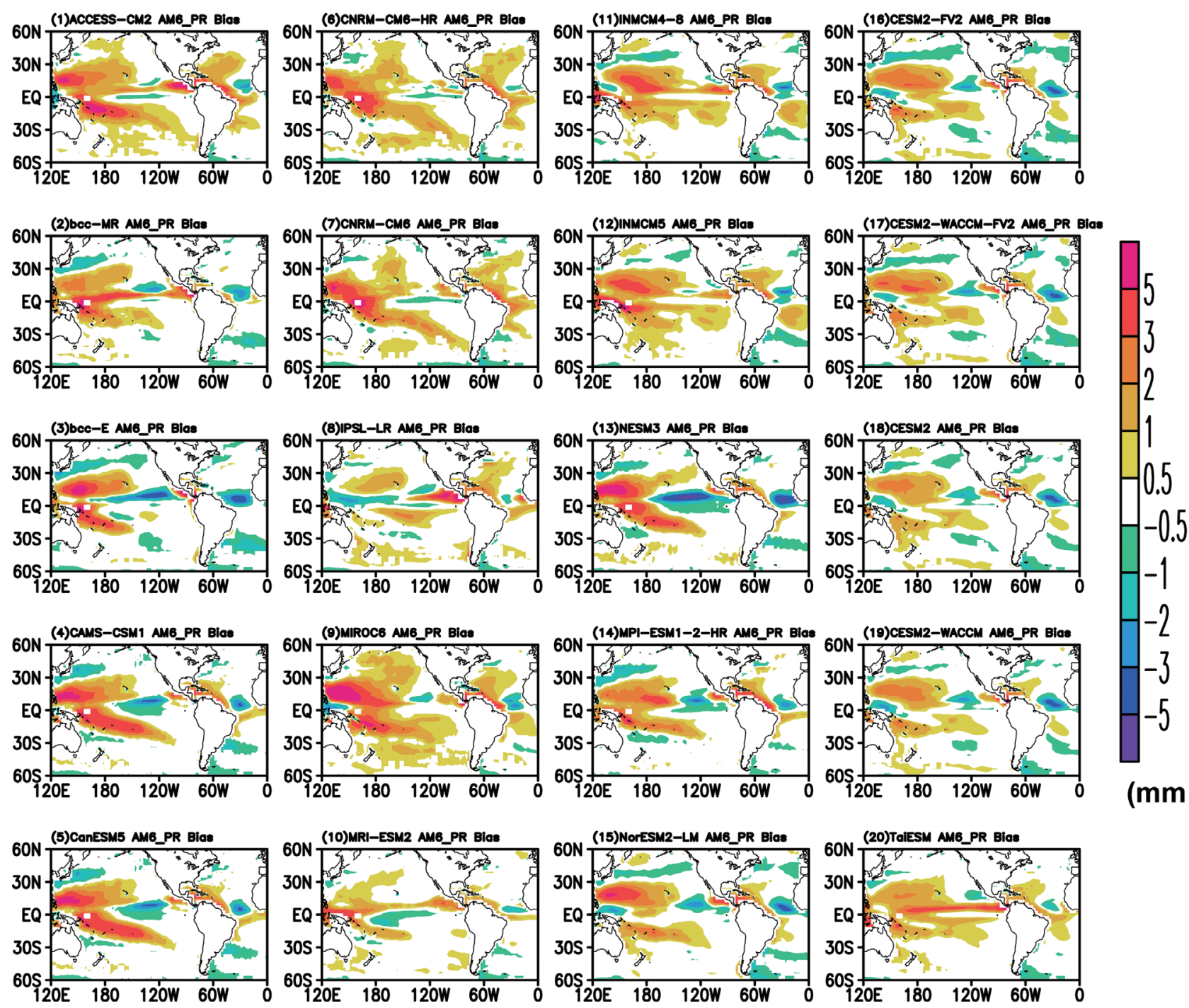

Fig. A8. Same as Fig. A2 but for surface precipitation rate (square) against GPCP. 

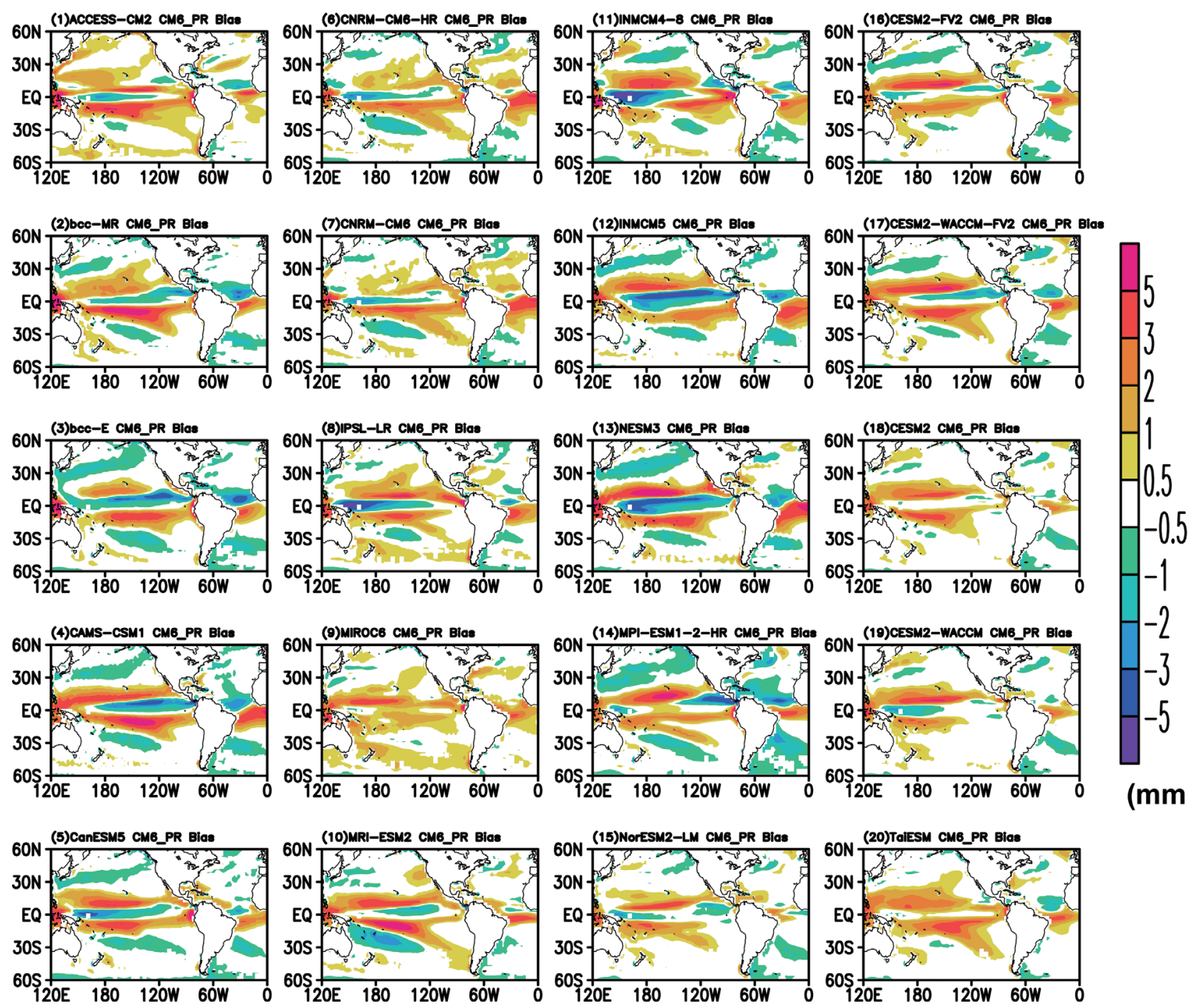

$\left(\mathrm{mm} \mathrm{d}^{-1}\right)$

Fig. A9. Same as Fig. A8 but for CMIP6. 